\title{
Brain-wide maps of Fos expression during fear learning and recall
}

\author{
Jin-Hyung Cho, ${ }^{1}$ Sam D. Rendall, ${ }^{1}$ and Jesse M. Gray \\ Genetics Department, Harvard Medical School, Boston, Massachusetts 02115, USA
}

\begin{abstract}
Fos induction during learning labels neuronal ensembles in the hippocampus that encode a specific physical environment, revealing a memory trace. In the cortex and other regions, the extent to which Fos induction during learning reveals specific sensory representations is unknown. Here we generate high-quality brain-wide maps of Fos mRNA expression during auditory fear conditioning and recall in the setting of the home cage. These maps reveal a brain-wide pattern of Fos induction that is remarkably similar among fear conditioning, shock-only, tone-only, and fear recall conditions, casting doubt on the idea that Fos reveals auditory-specific sensory representations. Indeed, novel auditory tones lead to as much gene induction in visual as in auditory cortex, while familiar (nonconditioned) tones do not appreciably induce Fos anywhere in the brain. Fos expression levels do not correlate with physical activity, suggesting that they are not determined by behavioral activitydriven alterations in sensory experience. In the thalamus, Fos is induced more prominently in limbic than in sensory relay nuclei, suggesting that Fos may be most sensitive to emotional state. Thus, our data suggest that Fos expression during simple associative learning labels ensembles activated generally by arousal rather than specifically by a particular sensory cue.
\end{abstract}

[Supplemental material is available for this article.]

Neuronal activity-regulated genes, including the prototypical immediate early gene Fos, are powerful tools for labeling neuronal ensembles based on their history of neuronal activity (Barth 2007; Kawashima et al. 2014; Mayford and Reijmers 2015). Fos is a transcription factor that is robustly induced by neural activity in vitro (Greenberg et al. 1986; West et al. 2002; West and Greenberg 2011). In vivo, it is induced in many brain regions in response to a wide variety of external stimuli (Morgan et al. 1987; Senba and Ueyama 1997; Tischmeyer and Grimm 1999). Its induction is rapid in onset $(5-10 \mathrm{~min})$ and transient in duration ( $2-3 \mathrm{~h})$, such that Fos mRNA levels reflect the extent of neuronal activity in the several hours leading up to a measurement. In the hippocampus, Fos is induced in ensembles whose activity is driven by a specific physical environment (Guzowski et al. 1999). Impressively, artificial reactivation of $\mathrm{Fos}^{+}$hippocampal ensembles encoding a fear-associated environment induces fearrelated behaviors (Garner et al. 2012; Liu et al. 2012; Denny et al. 2014). os $^{+}$ensembles in the hippocampus may therefore reveal "memory traces" or engrams that are the physical substrate of associative memories in the brain (Lashley 1950; Josselyn et al. 2015).

Brain-wide measurement of Fos expression has the potential to enable the identification of engram-containing ensembles throughout the brain. Serial two-photon tomography enables quantification of Fos reporter expression brain-wide (Kim et al. 2015; Vousden et al. 2015). For detection of endogenous expression, brute force sectioning and in situ hybridization is becoming more practical with semi-automated analysis pipelines (Wheeler et al. 2013). Most promisingly, immunohistochemical staining of cleared brain tissue (e.g., using iDISCO or CLARITY) promises to reduce by an order of magnitude the imaging time required for brain-wide assessment of Fos expression (Renier et al. 2014, 2016). Rapidly, the technical barriers that have historically

1These authors contributed equally to this work.

Corresponding author: gray@genetics.med.harvard.edu

Article is online at http://www.learnmem.org/cgi/doi/10.1101/lm.044446. 116. made it difficult to perform and interpret brain-wide assessments of Fos expression are being overcome.

Nevertheless, beyond the hippocampus and its associated circuitries, the relationship between Fos $^{+}$ensembles and associative memory engrams is not known. Fos can be induced both by emotional arousal and by specific sensory cues. In limbic regions, such as the periaqueductal gray and the paraventricular nucleus of the hypothalamus, $\mathrm{Fos}^{+}$ensembles are highly sensitive to emotional arousal (Cullinan et al. 1995; Senba and Ueyama 1997). In contrast, in sensory cortex, Fos ensembles are sensitive to specific sensory cues. Whisker stimulation induces Fos specifically in primary somatosensory cortex, and exposure to light induces Fos specifically in visual cortex (Rosen et al. 1992; Beaver et al. 1993; Melzer and Steiner 1997). Yet even in regions such as sensory cortex that are devoted to sensory processing, emotional signals can also induce gene induction and spiking (Letzkus et al. 2011; Peter et al. 2012). Sensory cortex may be similar to the amygdala, where it is clear that principal cells detect both sensory cues and emotional state (Johansen et al. 2011). Indeed, Fos in the amygdala is sometimes induced by the coincidence of neutral and emotionally salient stimuli, thereby potentially encoding an emotional association (Josselyn et al. 2015). In this study, we were motivated by the idea that high quality brain-wide maps of Fos could distinguish brain regions in which Fos induction is dependent on specific sensory cues, emotional arousal, or the coincidence of both. Having such a brain-wide map would facilitate the cellularlevel determination of neural circuitry for emotional learning and memory on a global scale.

To evaluate the contributions of sensory cues and emotional state to Fos expression during simple associative learning, we generated brain-wide maps of Fos expression after fear conditioning

(C) 2017 Cho et al. This article is distributed exclusively by Cold Spring Harbor Laboratory Press for the first 12 months after the full-issue publication date (see http://learnmem.cshlp.org/site/misc/terms.xhtml). After 12 months, it is available under a Creative Commons License (Attribution-NonCommercial 4.0 International), as described at http://creativecommons.org/licenses/by$\mathrm{nc} / 4.0 /$. 
and fear recall. To analyze these maps, we developed a new computational pipeline for brain-wide quantification of endogenous Fos expression using fluorescence in situ hybridization (FISH). Our pipeline identifies $\mathrm{Fos}^{+}$cells using a convolutional neural network and assigns each cell to an Allen Brain Atlas region. Using this pipeline, we find that auditory fear conditioning produces a distinctive brain-wide pattern of Fos mRNA induction throughout most of the cortex and in subsets of thalamic and hypothalamic nuclei. This pattern of Fos induction is not specific to auditory circuits and is recapitulated by painful unconditioned stimuli alone. Similar brain-wide patterns of Fos induction are elicited by fear recall or novel tone. Thus, our data suggest that Fos expression during simple associative learning labels ensembles activated generally by arousal rather than specifically by a particular sensory cue.

\section{Results}

To create high-quality brain-wide maps of endogenous Fos mRNA induction, we combined established fluorescent in situ hybridization (FISH) technology with a semi-automated image registration and cell detection pipeline (Fig. 1A). We generated 540 brain sections per mouse (20 $\mu \mathrm{m}$ thickness), performed FISH on every sixth section, and imaged at $10 \times$ resolution. We registered the images of Hoechst-stained tissue sections to the Allen Brain Atlas

A

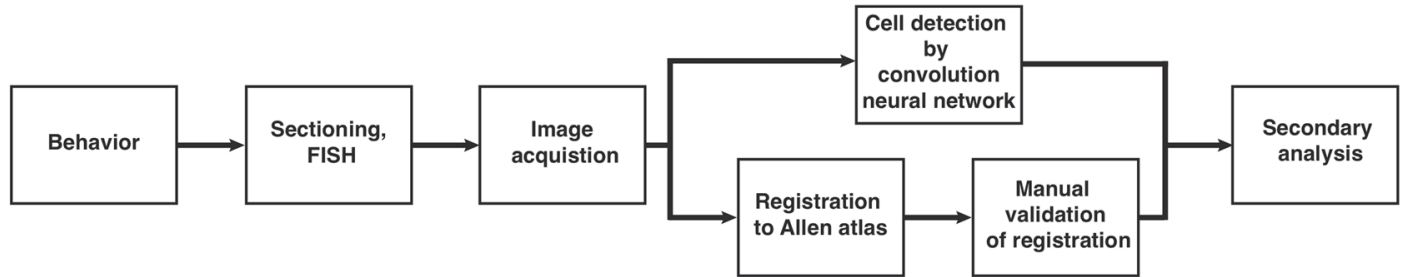

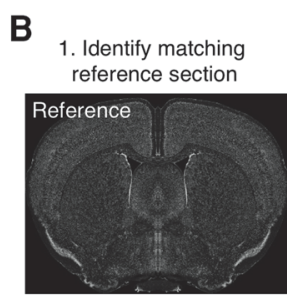
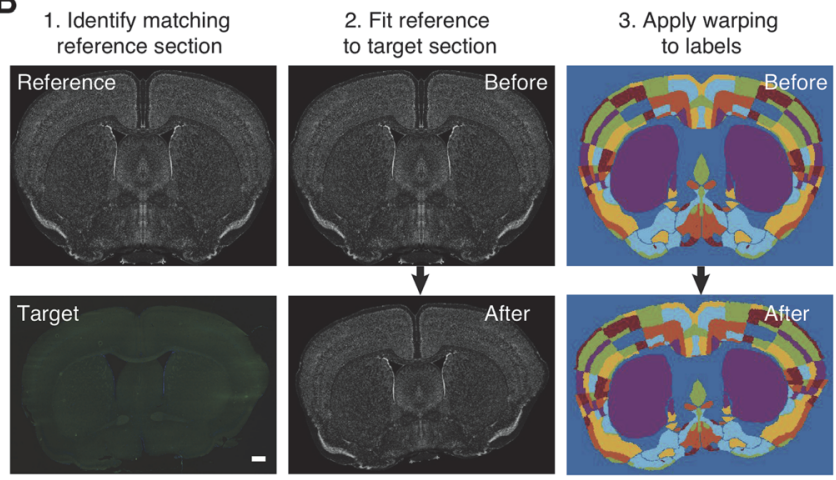

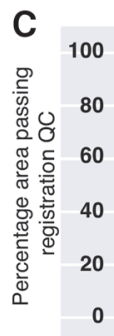
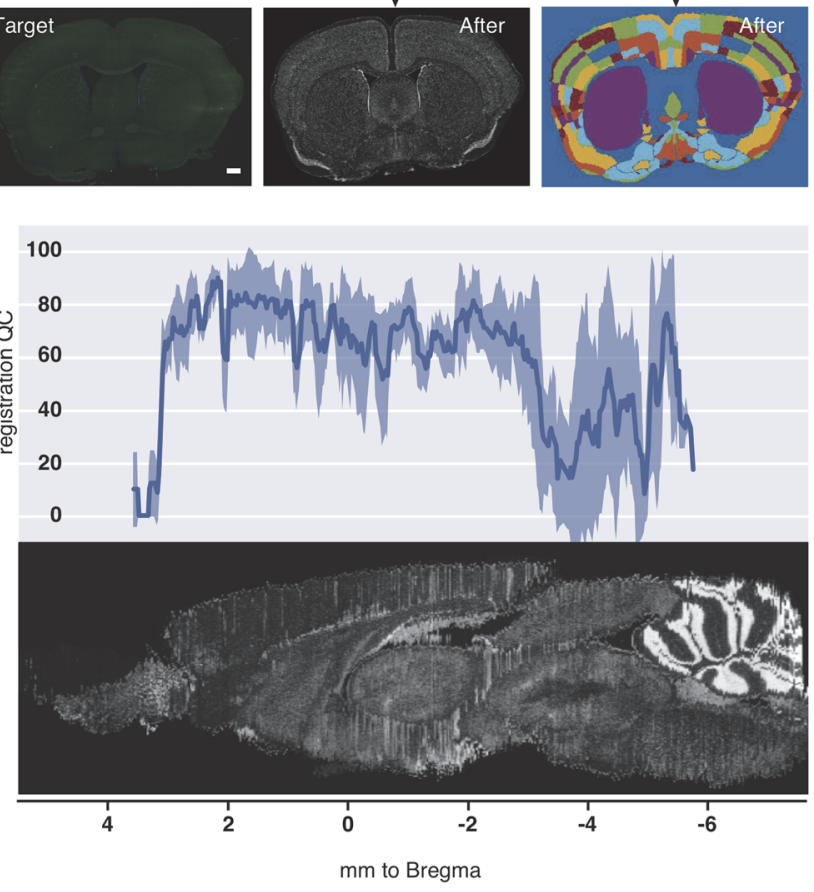
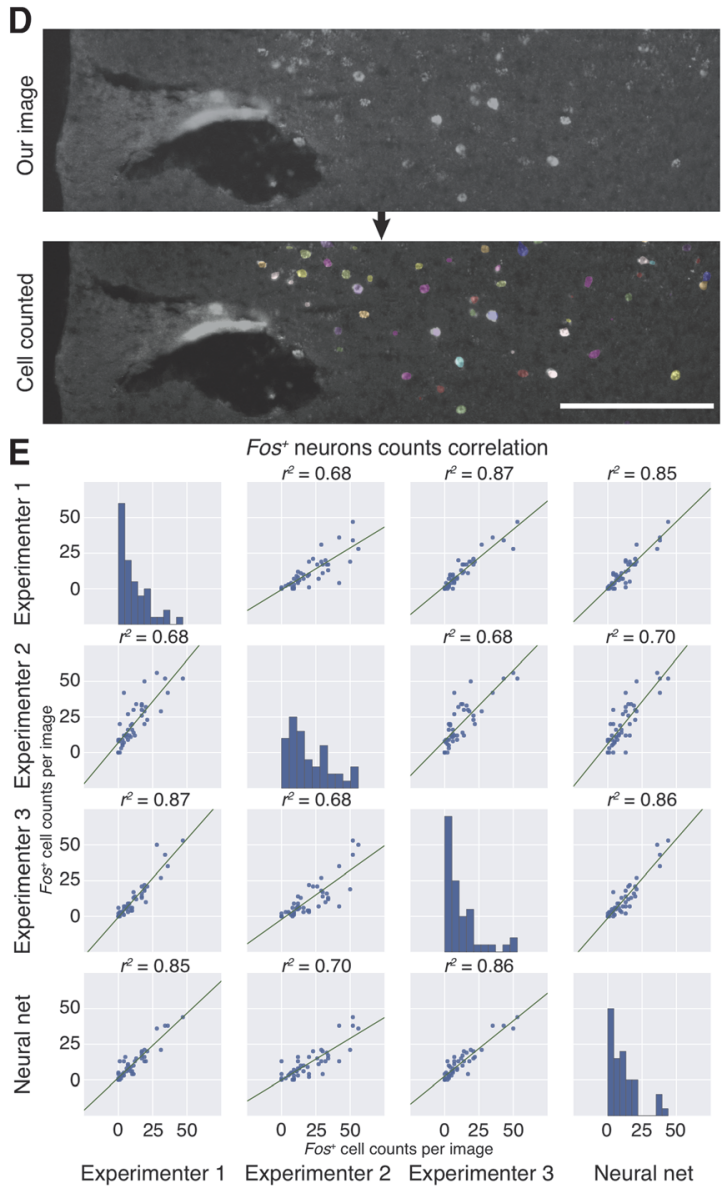

Figure 1. Brain-wide quantification of endogenous Fos expression via a semi-automated image analysis pipeline. (A) Schematic representation of our analysis pipeline. (B) Example of brain section registration to a corresponding coronal section from the Allen Brain Atlas (ABA). (1) For each target section, the appropriate reference section was chosen from the ABA. (2) A transform relating the ABA reference section to the Hoechst stained target section was computed. (3) Using this transform, the region labels were warped to fit the target section. Scale bar: $500 \mu \mathrm{m}$. (C) Percentage of brain section area at each sagittal position for which registration was deemed to be successful based on region-by-region visual inspection. Error bars indicate \pm SEM. (D) Example cell detection by convolutional neural network, with all identified cells/objects colored uniquely. Scale bar: $250 \mu \mathrm{m}$. (E) Off Diagonal: scatter plots comparing $\mathrm{Fos}^{+}$cell counts reported by each scorer, and by the neural network. On Diagonal: histogram of cell counts reported by each scorer. Each dot is one of 46 images analyzed in our QC set. 
common coordinate framework with a pipeline built on the Insight Segmentation and Registration Toolkit (ITK) (see Materials and Methods). We assessed registration quality via manual inspection of every section and region so that only regions that registered accurately would be included in subsequent analyses (Fig. 1B,C). We identified Fos $^{+}$cells using a convolutional neural network $(\mathrm{CNN})$ trained on 139 human-annotated training images (Fig. 1D, see Materials and Methods). We evaluated CNN performance against 46 distinct ground-truth images that were manually annotated by three independent experimenters. We found that the cell counts produced by the CNN were well correlated with human counts, and that its accuracy was comparable to that seen between independent human scorers (Fig. 1E; Supplemental Fig. 1). Our subsequent analyses compare $\mathrm{Fos}^{+}$ cell counts between mice, without regard to cell intensity. However, we also provide the intensity of Fos expression across conditions and regions (Supplemental Fig. 2).

Before performing brain-wide quantification of $\mathrm{Fos}^{+}$cells, we sought to address a longstanding experimental confound in the interpretation of Fos expression: the induction of Fos that occurs when mice are handled by an experimenter and transferred between cages. To minimize handling-induced Fos induction, conventional auditory fear conditioning experiments are typically preceded by several days of habituation to handling, which reduces Fos induction due to handling on the day of the experiment (Fig. 2A; Campeau et al. 1991). However, we found using FISH that $4 \mathrm{~d}$ of habituation (one trial at $20 \mathrm{~min}$ per day) is insufficient to prevent Fos induction in the amygdala and auditory cortex (Fig. 2B-D). Therefore, to eliminate Fos induction due to handling, we developed a home cage auditory fear conditioning system (Gruene et al. 2016). In this variation of fear conditioning, a mouse lives in a conditioning cage for $3 \mathrm{~d}$ (allowing 24-h per day habituation), and the conditioning is commenced without experimenter handling (Fig. 2E). Unlike $4 \mathrm{~d}$ of habituation to handling, we found that the home cage conditioning system is effective at reducing Fos expression in the amygdala and auditory cortex to levels statistically indistinguishable from those in mice living undisturbed in standard facility cages (Fig. 2H). As in standard fear conditioning, Fos induction in the amygdala and cortex can be detected with our home cage fear conditioning system (Fig. 2F-H). By eliminating Fos induction due to handling, home cage fear conditioning enables us to accurately relate Fos induction after auditory fear conditioning to specific elements of the fear conditioning experience itself.

We sought to characterize the behavior of mice during home cage fear conditioning and recall, with the goal of assessing the effectiveness of this paradigm. We first conditioned mice in home cages and assessed recall conventionally 1 mo later, revealing that home cage fear conditioning is an effective way to fear condition mice (Supplemental Fig. 11). Next, we analyzed behavior during home cage recall, which differs from conventional recall in that mice have been present in the chamber for several days prior to the recall test. After acclimating to our home cage auditory fear conditioning system for $3 \mathrm{~d}$, mice moved very little, alternating between grooming, sitting, or sleeping (Fig. 3; Supplemental Movies). This inactivity contrasts with the high level of baseline activity typically observed in the tens of minutes after cage transfer, when conventional recall testing is usually performed. Because of the inactivity of mice in our assay, we found that it is not possible to assess home cage recall conventionally by analyzing freezing. We infer that conventional detection of freezing may rely on the elevation of locomotor activity that occurs upon cage transfer. However, recall led to increases in breathing rate and locomotory activity (Fig. 3C, $P<0.05$, $t$-test) that enabled us to distinguish control and recall conditions with $87 \%$ accuracy in a blinded test (Supplemental Table 3; Supplemental Movies), sug- gesting that fear recall does take place. We conclude that home cage fear conditioning is effective.

We performed home cage auditory fear conditioning and quantified the density of $\mathrm{Fos}^{+}$cells in fear conditioned and nonfear conditioned (context-only) mice throughout the brain (Fig. 4A,B; Supplemental Tables 1, 2). We define normalized Fos induction as a change in this cell density between the conditioned and control conditions. As a positive control, we first sought to confirm in our system that Fos is induced in brain regions that typically show robust Fos induction (Pezzone et al. 1992, 1993; Smith et al. 1992) or are required for fear learning (Johansen et al. 2011; Tovote et al. 2015). We confirmed that in our system, there is Fos induction in the amygdala, the best-studied brain region in fear conditioning paradigms (Fig. 4A,B, $t$-test-derived FDR $<0.05$ for BLA and $<0.1$ for LA). In addition, the prefrontal and auditory cortices (ILA, PL; AUD), and paraventricular nucleus of the thalamus (PVT) each have statistically significant increases in Fos+ neurons (FDR < 0.05). Thus, we are able to detect Fos induction in regions previously reported to be induced.

We used our brain-wide Fos data to address a series of predictions of two competing models of fos induction during simple associative learning. In the first model, ensembles labeled by Fos or other immediate early genes encode specific sensory cues or their association with emotional state, as is often assumed (Sacco and Sacchetti 2010; Kwon et al. 2012). In the second model $\mathrm{Fos}^{+}$ensembles instead express Fos entirely as a consequence of generalized emotional arousal (Cullinan et al. 1995; Senba and Ueyama 1997). Arousal could lead to Fos induction directly or could generically potentiate the influences of sensory experience generally on brain activity. We reasoned that if $\mathrm{Fos}^{+}$ensembles encode specific sensory representations (model 1), auditory fear conditioning would selectively activate auditory, compared with visual, areas. We found that instead, auditory fear conditioning leads to Fos induction in a majority (70\%) of brain regions analyzed, including all of the cortex (FDR 20\%; Fig. 4B; Supplemental Figs. 3, 4). Auditory regions generally do not stand out as most-induced by fear conditioning (Fig. 4B; Supplemental Fig. 9). Fos induction in auditory relay thalamus (MG) is no stronger than that in visual relay thalamus (LGd), and auditory cortex is no more induced than visual cortex $(P>0.05$, $t$-test; Fig. $4 \mathrm{~B})$. Nor is Fos induction easily understood more generally in terms of nucleus-to-nucleus mesoscale circuit connectivity (Supplemental Fig. 5), based on an existing data set (Oh et al. 2014). Thus, surprisingly, Fos induction after auditory fear conditioning shows no specificity for auditory circuits, nor for any particular mesoscale connectivity.

We asked whether Fos induction during fear conditioning was instead specific to brain regions required for processing emotional arousal (again using a 20\% FDR threshold for Fos induction, Supplemental Fig. 4A). Fos-inducing subregions include the amygdala (LA, BLA, CEA), lateral septum (LS, SH), and bed nucleus of the striatum (BST), which function in fear- and anxiety-related behaviors (Tovote et al. 2015); the hypothalamic paraventricular and anterior nuclei (PVH, AHN), lateral hypothalamic area (LHA), and preoptic area (LPO), which function in stress and anxiety (Smith and Vale 2006; Anthony et al. 2014); the ventral striatum (ACB), which processes emotional and motivational content (Levita et al. 2002); and the subiculum (SUB, PRE, POST), which functions in emotional arousal (Fig. 4B; Supplemental Fig. 4; Maren 1999; O'Mara 2005; O'Mara et al. 2009). In contrast, subregions less associated with emotional arousal tend to induce little Fos. These subregions include the dorsal striatum (GP); the arcuate, periventricular, supraoptic, and tuberomammilary nuclei of the hypothalamus (PVi, ARH, SO, TMv); the cerebellum (CBX) and other hindbrain areas (HB) (Supplemental Fig. 6); and the hippocampus (CA3, DG; Figs. 4B, 5B). The hippocampus is most responsive to spatial novelty (Radulovic et al. 1998) and is 
A Habituation for conventional cued conditioning
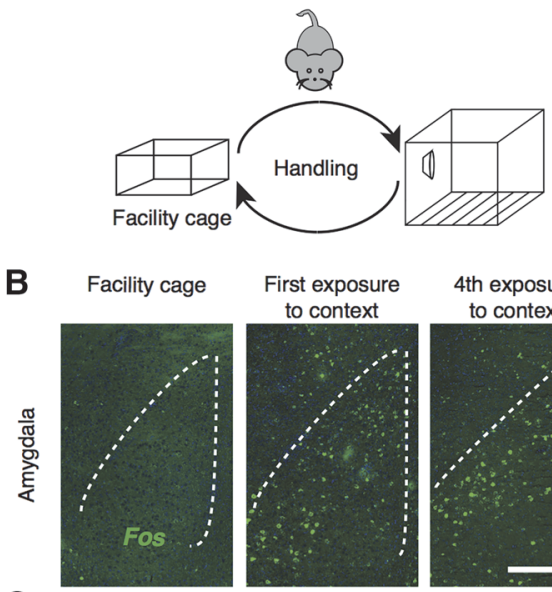

C

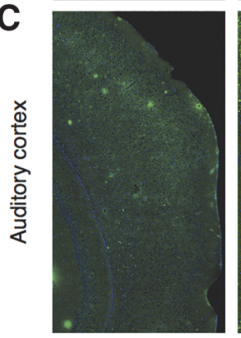

D 0.7

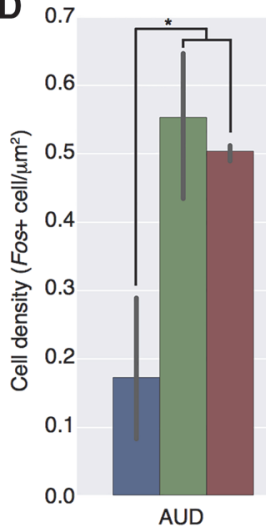

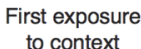
to context
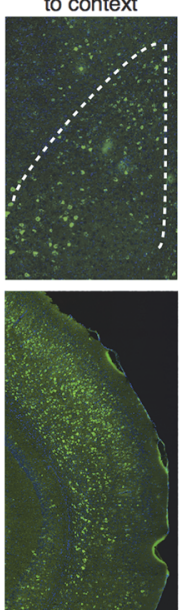

4th exposure to context
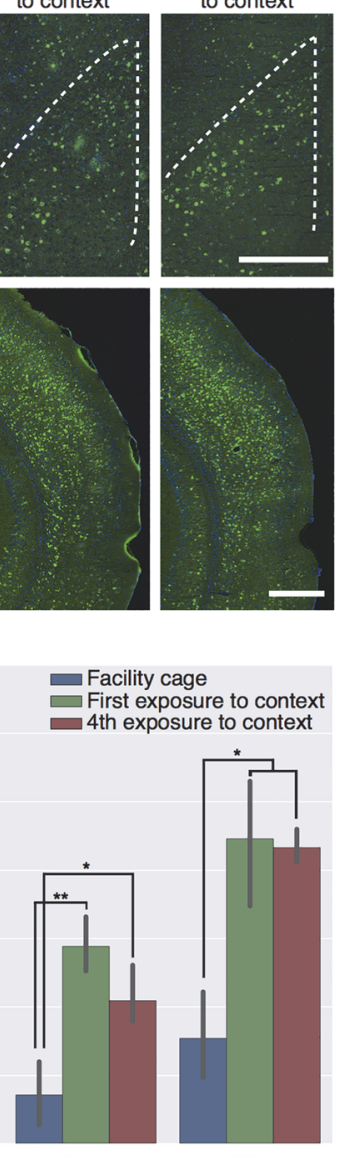

BLA

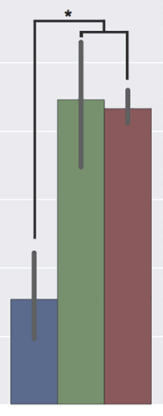

TEa
E Home cage cued conditioning

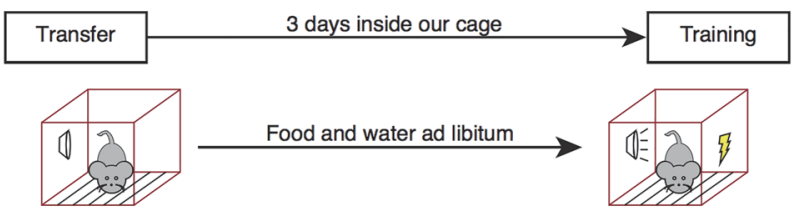

$\mathbf{F}$
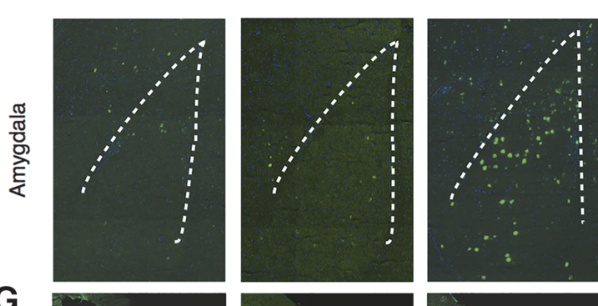

Fear conditioned
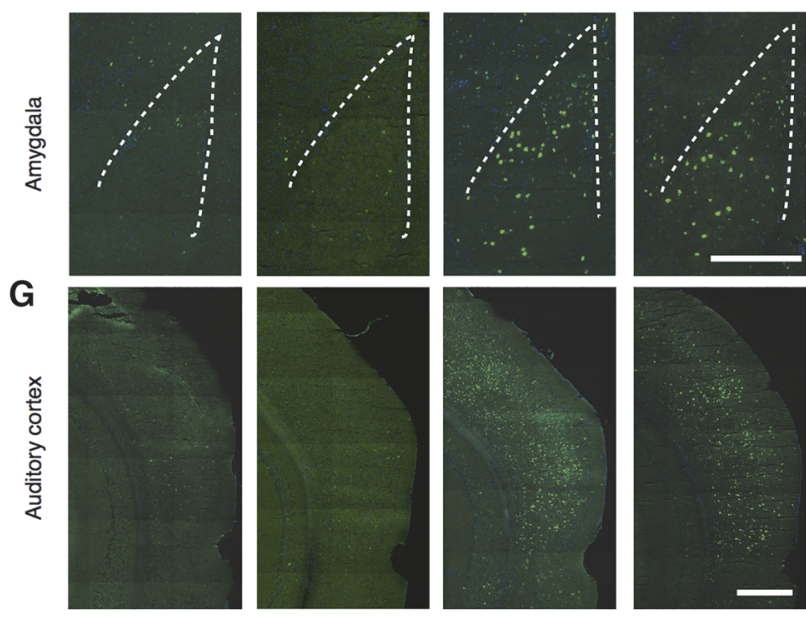

$\mathbf{H}$

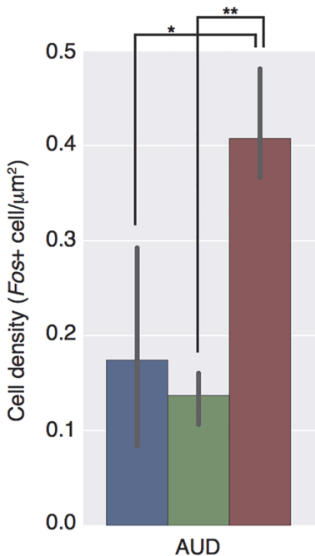

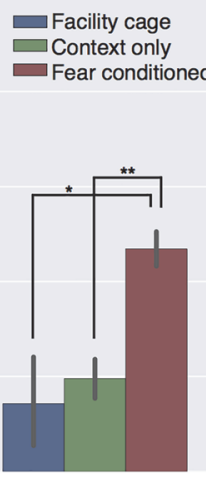

BLA

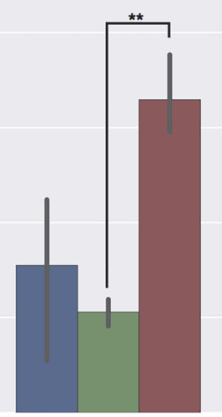

TEa

Figure 2. Home cage cued fear conditioning eliminates Fos mRNA induction due to experimenter handling. ( $A$ ) Schematic representation of the habituation protocol typically used to acclimate mice to handling and standard conditioning chambers. Representative images showing Fos ${ }^{+}$neurons in the $(B)$ amygdala and in the $(C)$ auditory cortex after transfer to the standard conditioning chamber, compared with mice left in facility cages. Transfer was performed after 0 or $3 \mathrm{~d}$ of habituation (testing first exposure and fourth exposure). (D) Quantification of Fos ${ }^{+}$cell density in the auditory cortex (AUD), basolateral amygdala (BLA) and temporal association areas (TEa) from panels $(B, C)$. Error bars indicate $\pm 68 \%$ confidence interval. (E) Schematic representation of home cage conditioning, where mice are housed in the conditioning context for $3 \mathrm{~d}$ prior to training. Representative images showing Fos ${ }^{+}$neurons in the $(F)$ amygdala and in the $(G)$ auditory cortex following home cage cued conditioning chamber housing-only or fear conditioning, compared with mice left in facility cages. (H) Quantification of Fos ${ }^{+}$cell density from panels $F, G . N=3$ for each condition. $\left(^{*}\right) P<0.05,\left({ }^{* *}\right) P<0.005, t$-test. Scale bars: $500 \mu \mathrm{m}$.

required for contextual but not auditory fear conditioning (Selden et al. 1991; Kim and Fanselow 1992; Phillips and LeDoux 1992). Although our automated cell counting may have missed subregion-specific induction in the cerebellum and hindbrain due to difficulty in atlas registration (Fig. 4B; Supplemental Figs. $5,6)$, manual inspection corroborates the lack of induction in these areas. In summary, Fos tends to be induced in subregions that are functionally important for processing emotional arousal but not in other brain regions, consistent with the idea that the primary determinant of Fos induction is emotional arousal.

In the thalamus and cortex, we asked whether the specific subregions with the biggest increases in $\mathrm{Fos}^{+}$cell density during fear conditioning are associated with the processing of sensory cues or emotional state. In the thalamus, nuclei cluster based on Fos expression into two major groups (Figs. 4B, 5A) defined by their functionality and connectivity (Vertes et al. 2015). Primary (i.e., relay) nuclei associated with specific sensorimotor functions do not show significant induction (MG, VP, VAL, and VM with FDR $>0.2$; PO is marginal with $\mathrm{FDR}=0.196$, and visual $\mathrm{LGd}$ is an exception with FDR $<0.2$ ) (Fig. 4B, red text; Fig. 5A). In contrast, "limbic" or poly-association nuclei show strong induction (AV, AM, AD, IAD, IMD, IAM, MD CM, PVT, RH, RE, LD; FDR < 0.2 ) (Fig. 4B, blue text; Fig. 5A). In the cortex, subregions involved in emotion and pain processing (ACA, SS, AI) show Fos induction, 
A
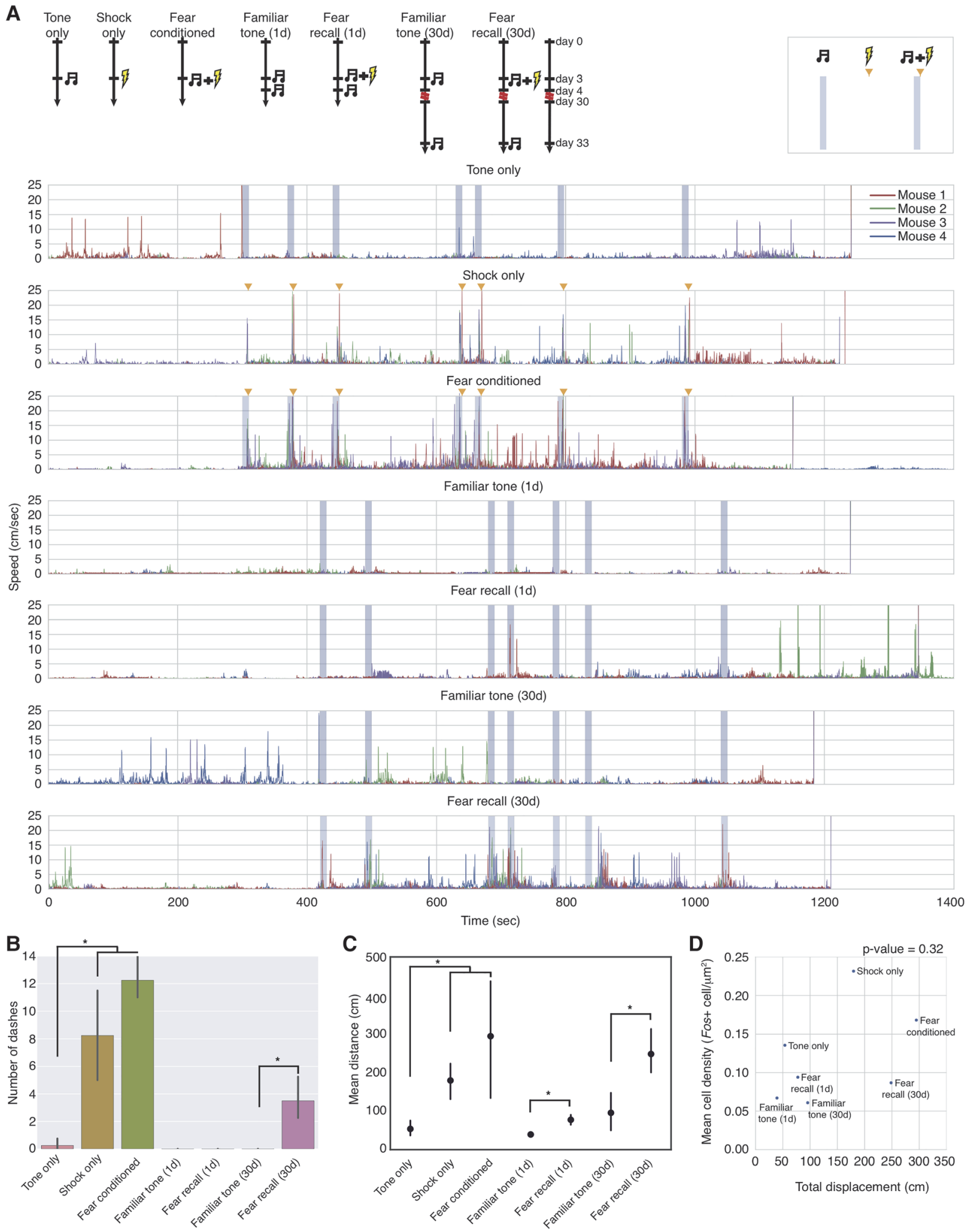

Figure 3. Behavioral analysis of home cage fear conditioning and recall. (A) The instantaneous speed of each mouse throughout each session of behavior. The 10-sec intervals during which tones occurred are shaded in blue, and the shock is depicted by an orange vertical line. (B) Human visual assessment of dashing behavior during each $10 \mathrm{sec}$ tone, or during the shock and the nine seconds leading up to it, as shaded in blue in panel $A$. (C) The total distance traveled by mice in each behavioral condition over the $12 \mathrm{~min} 40 \mathrm{sec}$ following the first tone and/or shock, calculated from the data in panel $A$. (D) Scatterplot and regression analysis of the relationship between the mean total distance traveled by mice in each condition (shown in panel $C$ ) and the mean density of Fos ${ }^{+}$cells brain-wide. In all panels, error bars are $\pm 1 \mathrm{SE}, n=4$ mice, and $\left.{ }^{*}\right) P<0.05, t$-test, except that in panel $D$, only three mice were quantified for Fos. 


\section{A}

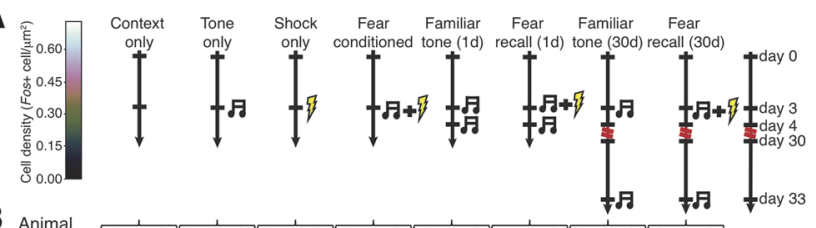

B

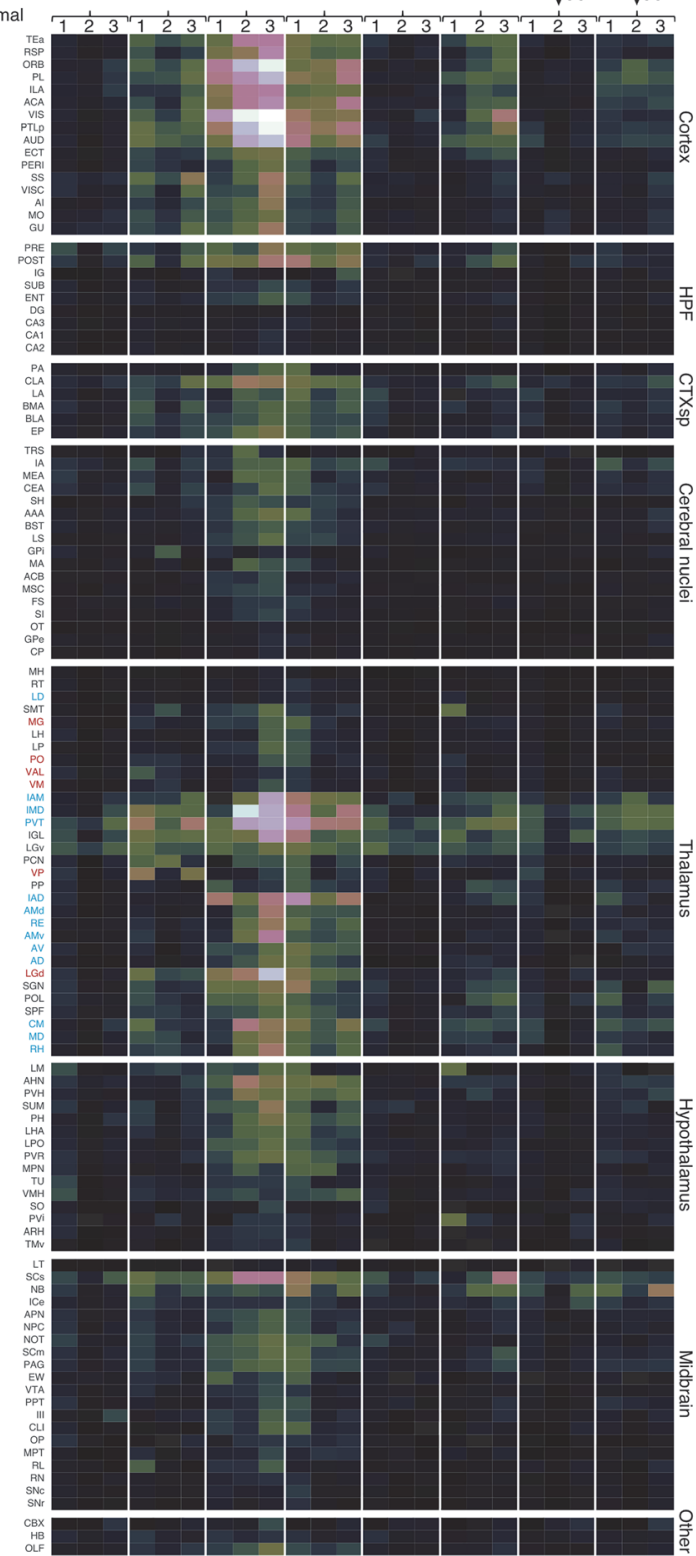

Figure 4. Brain-wide $\mathrm{Fos}^{+}$cell densities following fear conditioning, recall, and control conditions. (A) Schematics of behavioral protocols for each experimental condition. The four left-most conditions are fear conditioning (training) and three control conditions. The four right-most conditions are fear recall (testing) and corresponding control conditions performed $1 \mathrm{~d}$ or 1 mo post-training. (B) Heat map of Fos ${ }^{+}$cell density across brain regions (rows), conditions (sets of three columns), and individual mice (columns). The thalamic regions in red represent primary relay nuclei while the regions in blue represent poly-association nuclei. Within major brain regions, subregions are clustered by Fos ${ }^{+}$cell density across conditions. The results of statistical comparisons of each condition to the context condition are shown in Supplemental Figure S4. To enable comparisons between any two conditions, in situ hybridization was performed in nine batches that each included one-third of the analyzed brain sections (rostral, middle, or caudal sections) from eight out of 24 mice (one mouse from each condition). Cell counts and region areas used to compute cell densities are in Supplemental Tables 1, 2. yet other areas including visual cortex (VIS), auditory cortex (AUD), and orbitofrontal cortex (ORB) show as much or more Fos induction (Fig. 4B). Interestingly, within sensory cortex, primary auditory and primary visual cortex are among the regions showing the strongest induction (Supplemental Fig. 7). Thus, Fos induction during fear conditioning is biased toward limbic over sensory areas in the thalamus and shows little modality-bias in the cortex.

A prediction of the model that $\mathrm{Fos}^{+}$ensembles encode specific sensory representations is that the auditory tone (conditioned stimulus, CS) should be required for the Fos induction that occurs during fear conditioning. However, we found that the shock-only (unconditioned stimulus, US) condition generally recapitulates gene induction seen during fear conditioning, with no regions exhibiting higher induction in the fear conditioned than the shock-only group (FDR $<0.05$, Fig. 4B; Supplemental Fig. 9). If anything, there is more induction in the shock-only than fear conditioning group, although the difference is not statistically significant. Novel tone alone (tone-only) also induces Fos in a similar pattern to fear conditioning or shock $\left(r^{2}>0.5, P<\right.$ 0.01; Supplemental Figs. 9, 10), albeit to a lesser extent in almost every brain region. Like fear conditioning, the tone-only condition shows no bias toward auditory brain regions: visual and auditory cortex have similar induction of $\mathrm{Fos}^{+}$cells, and auditory relay thalamus (MG) is induced no more than auditory visual thalamus (LGd) $(P>0.05, t$-test; Fig. $4 \mathrm{~B})$. These results suggest that $\mathrm{Fos}^{+}$ neurons induced by shock and tone pairings are activated by emotional arousal, not specific sensory cues such as the tone.

Fos induction due to emotional arousal could be direct (i.e. the circuit activity associated with an emotion itself) or indirect (e.g., emotion that induces attentional or behavioral changes that strengthen responses to sensory stimuli). To investigate whether changes in behavior could be driving Fos induction, we characterized the movement during our behavioral experiments of the mice analyzed for Fos expression. Overall, there was not a significant correlation between physical activity and Fos induction (Fig. 3B-D), and in particular the tone-only mice moved very little despite inducing Fos. These results suggest that the gene induction we observed is not the consequence of a specific behavior or motor pattern (Fig. 3A,B).

We compared tone-only with shock-only conditions to identify regions that might distinguish emotional arousal in the absence of physical pain from physical pain itself. In the top eight regions showing the most differential expression between fear conditioning and tone and those showing the most differential expression between shock and tone, five regions overlap (Supplemental Fig. 9). These are the medial preoptic nucleus (MPN, hypothalamus), the central linear nucleus raphe (CLI, midbrain), and the interanterodorsal, dorsal interomedial, and anterodorsal nuclei (IAD, AMd, AD; thalamus). These regions do not match perfectly with functional pain processing pathways, which for example are localized to the ventral (e.g., VP) rather than dorsal thalamus (Yen and $\mathrm{Lu}$ 2013). They may distinguish pain from emotional arousal, or they may simply have a higher threshold for activation by emotional arousal than subregions in which Fos is induced by tone-only.

We considered the idea that in some brain regions, Fos could label ensembles whose activity is sensitive to specific sensory representations regardless of their novelty or emotional context. We hypothesized that in such regions, the presentation of familiar and novel auditory tones should lead to similar Fos induction. To test this hypothesis, we re-presented familiar (neutral) auditory tones $1 \mathrm{~d}$ or $1 \mathrm{~m}$ after initial presentation and quantified $\mathrm{Fos}^{+}$cell counts brain-wide. We found that presentation of familiar tones did not cause significant Fos induction at either time interval, despite novel tones leading to significant Fos induction (Fig. 4B; 
A
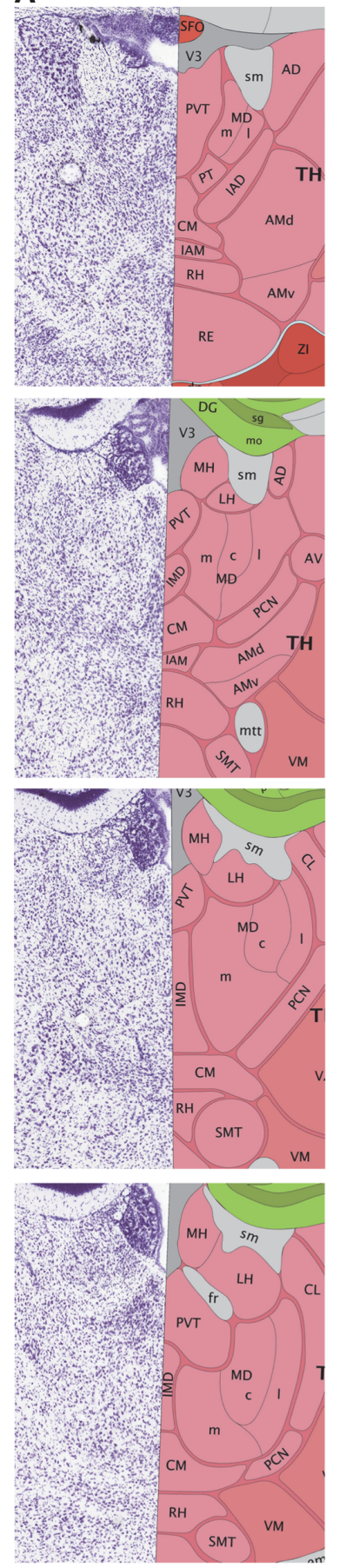

B

Context only
Context only
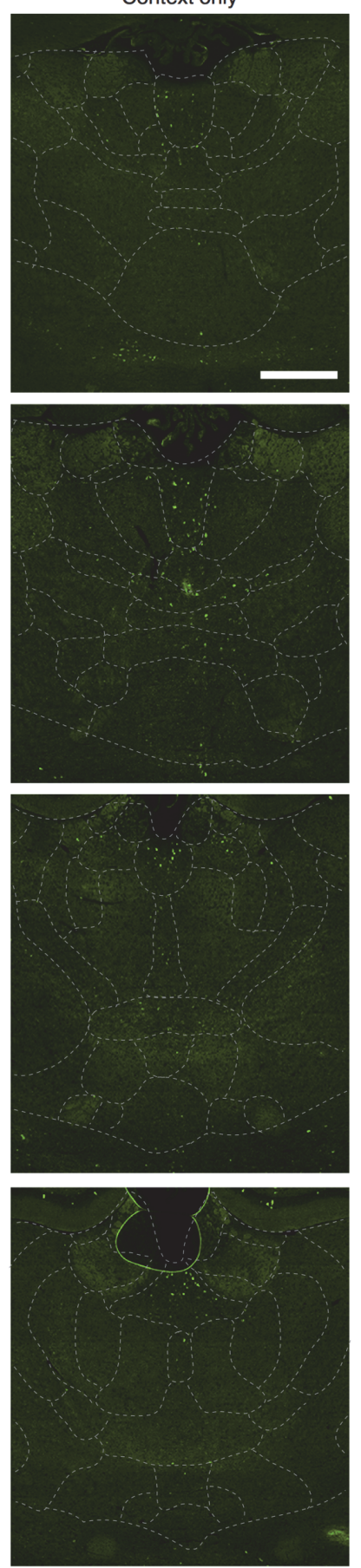

Tone only

Tone only
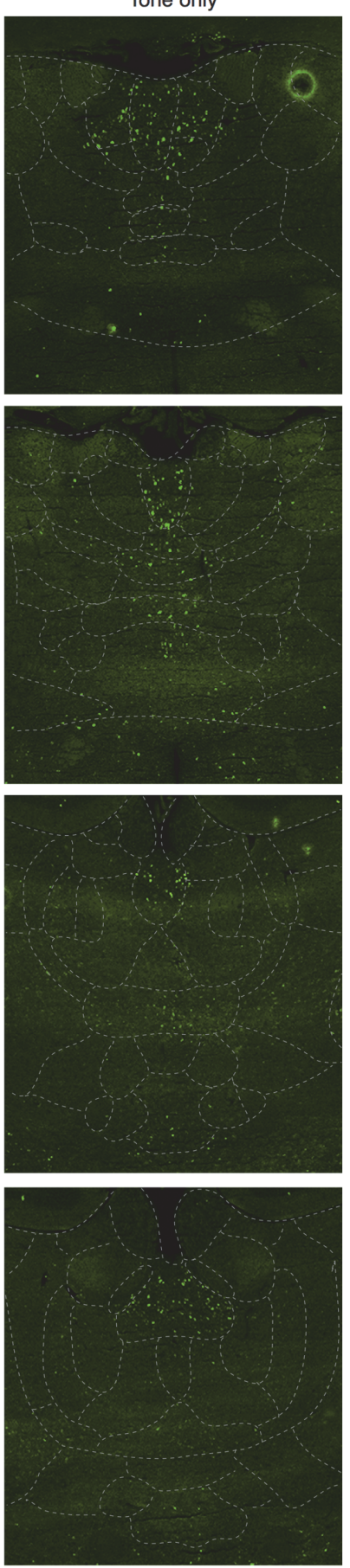
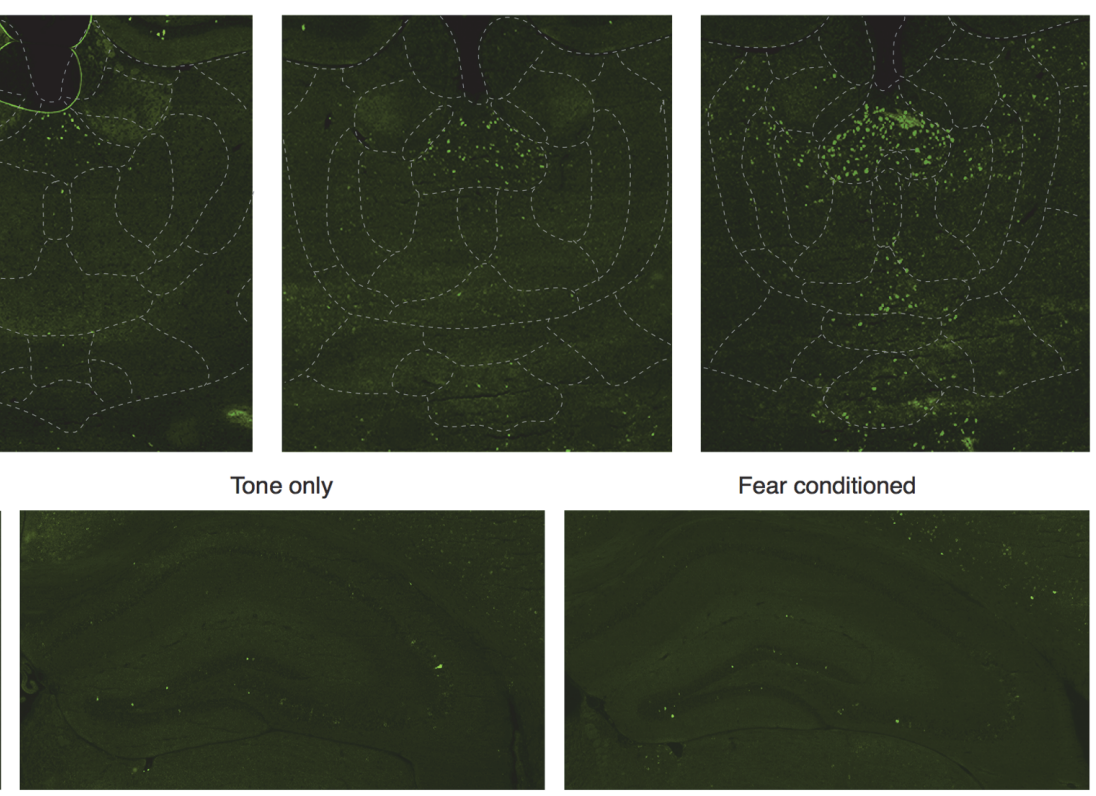

Figure 5. Fos induction upon fear conditioning and tone-only in the thalamus. (A) Representative images showing Fos ${ }^{+}$neurons along the rostral (top row) to caudal (bottom row) axis of thalamus in the context-only, tone-only and fear conditioned groups. (B) Representative images showing Fos ${ }^{+}$neurons in the hippocampus. Scale bars: $500 \mu \mathrm{m}$. 
Supplemental Fig. 8). The difference in Fos induction between novel and familiar tones is not a due to increased physical activity induced by novel tone, since there was as much $(1 \mathrm{~d})$ or more (30 d) movement after familiar tone presentations (Fig. 3C). The dependence of Fos induction on tone novelty is reminiscent of the general dependence of Fos induction on novelty (Tischmeyer and Grimm 1999), e.g., spatial novelty in the hippocampus (Radulovic et al. 1998). It suggests that if $\mathrm{Fos}^{+}$ensembles are responsive to specific auditory cues, the induction of Fos in these ensembles must also be dependent on cue novelty.

We investigated the possibility that a subset of $\mathrm{Fos}^{+}$neurons might be induced during fear conditioning via coincident detection of tone and shock and go on to encode a memory engram. One prediction of this model is that fear conditioning should induce more $\mathrm{Fos}^{+}$cells than tone-only or shock-only, and this is not the case (Fig. 4B; Supplemental Fig. 9). Another prediction is that $\mathrm{Fos}^{+}$ensembles should be responsive to presentation of conditioned but not naive auditory cues and therefore be more induced during fear recall than tone presentation alone. To address this possibility, we quantified $\mathrm{Fos}^{+}$cells after a recall test performed $1 \mathrm{~d}$ after conditioning. We found that the recall test induces a brain-wide pattern of Fos similar to tone-only (or to shock and fear conditioning) (Fig. 4B; Supplemental Fig. 10; $P<0.01$, $t$-distribution from Pearson's $r$ ). The density of $\mathrm{Fos}^{+}$cells upon recall and tone-only is highly correlated (Supplemental Fig. 10, $r=$ $0.77 ; P<0.01, t$-distribution from $r$ ). If anything, there may be more induction from tone-only than from recall: the tone-only group exhibited more (albeit not significantly more) induction than the recall group in a subset of cortical areas (SS, VISC, GU, AI, MO). This difference would be consistent either with a requirement for novelty for induction in these areas or with suppression of activity in these areas due to anticipation of footshock. Finally, upon recall, Fos induction is clearly visible not only in auditory but also visual and somatosensory cortices (Fig. 4B; Supplemental Figs. 7,9$)$. These results suggest that the act of recall may reactivate Fos throughout a broad circuit whose activity reflects emotional arousal.

Fos is not only frequently presumed to identify regions and cells that may contain a memory trace or engram (Josselyn et al. 2015; Mayford and Reijmers 2015), but also to be useful in tracking memory consolidation (Kwon et al. 2012; Wheeler et al. 2013), during which neural representations of an associative memory are altered over time (Frankland and Bontempi 2005). To test this idea brain-wide, we compared Fos induction after 1and 30-d recall tests. We found that the two conditions are indistinguishable in terms of Fos induction (Fig. 4B; Supplemental Fig. 8). This result suggests that to the extent that Fos induction during auditory fear conditioning reveals specific memory engrams, these engrams do not change during remote memory consolidation. A simpler interpretation-and one consistent with the striking similarity between novel tone presentation and fear recall-is that Fos induction during recall activates ensembles that are generally sensitive to emotional arousal.

\section{Discussion}

In this study, we generated high-quality brain-wide maps of Fos expression after auditory fear conditioning and recall. Our data consists of high-quality cell counts, enabling meaningful comparisons of endogenous Fos expression from one animal to another or one region to another across the entire brain. In generating these maps, we also developed new tools that we expect to be broadly useful: a home cage fear conditioning apparatus that eliminates the need for experimenter-handled habituation, a brain atlas registration tool that partially automates registration, and a con- volutional neural network that performs as well as human experts in cell identification. Each of these tools will be useful for asking directed questions about particular brain regions, in addition to enabling brain-wide experiments.

Our specific goal here was to investigate the extent to which $\mathrm{Fos}^{+}$ensembles induced during simple associative learning might encode specific sensory cues, such as the conditioned stimulus. Alternatively, $\mathrm{Fos}^{+}$could be induced directly or indirectly by emotional arousal and lack specificity for salient sensory information. Our data suggest that Fos induction during associative learning labels ensembles whose activation is arousal-dependent and that do not encode representations of specific, salient sensory events. First, Fos induction during auditory fear conditioning shows no specificity for auditory regions. Second, the patterns of Fos induction from tone-only, fear conditioning, shock-only, and recall conditions are similar. Third, unlike novel tones, familiar tones do not recapitulate the brain-wide patterns of Fos expression seen with fear conditioning. Curiously, whereas the simple auditory tones presented here lead to broad cortical Fos induction, exposure to light following hours of darkness can lead to specific Fos induction in visual cortex (Beaver et al. 1993). One interpretation is that Fos induction in the cortex is generally more sensitive to emotional state than to all but the most extreme sensory experiences.

The idea that during classical conditioning Fos ensembles throughout the brain are more sensitive to emotional arousal than specific sensory cues is in agreement with early studies on immediate early gene induction in the central nervous system, which examined Fos in response to various stressors (Senba and Ueyama 1997). However, under some conditions Fos and Arc in the amygdala are induced by coincidence of US and CS, specific to associative learning (Tischmeyer and Grimm 1999; Morrison et al. 2016; Rashid et al. 2016). We cannot rule out that specific neuronal subtypes behave differently than the averages that we observe here, that different activity-regulated genes may behave differently, or that lower tone or shock intensities would produce different results. However, we note that our $80 \mathrm{~dB}$ tone, 10-sec duration and, 0.5-mA shock intensities are within ranges (75-85 $\mathrm{dB}$; 0.5-0.7 mA) commonly used for fear conditioning mice(e.g., Han et al. 2008; Lamprecht et al. 2009; Kwon et al. 2012; Peter et al. 2012). The tone intensity we used is also below that reported to cause corticosterone release in rats (Campeau and Watson 1997). Our results suggest that emotional arousal is adequate to generate all of the Fos induction needed for acquisition and consolidation of remote emotional memories.

Fos induction during recall is increasingly used to identify regions and cells that may contain a memory trace or engram (Cowansage et al. 2014; Tanaka et al. 2014; Gouty-Colomer et al. 2015; Josselyn et al. 2015; Mayford and Reijmers 2015; Cai et al. 2016), with the expectation that engram-containing cells can be selected by virtue of their induction of immediate early genes both during learning and recall. However, our results suggest that the act of recall may reactivate Fos throughout a broad circuit for emotional arousal whose activity has no specific cue or engram dependence, beyond the ability of the cue to arouse. Even in auditory cortex, the induction of Fos in a neuron both during learning and recall may simply reflect the neuron's responsiveness to emotional arousal. This idea is consistent with neuroimaging data suggesting that emotional content is represented broadly throughout the brain (Lindquist et al. 2012); for example, visual cortex is sensitive to emotional content (Lang et al. 1998). In contrast, Fos induction in the hippocampus is driven far more by spatial novelty than emotional arousal (Fig. 4B, 5B), making the hippocampus ideal for the use of Fos to label a memory tracecontaining engram. We consider it interesting that the entire cortex induces Fos, given the importance of the cortex in long-term 
storage of associative memory (Frankland and Bontempi 2005; Sacco and Sacchetti 2010). We speculate that the strong bias of associative memory for emotionally salient content (Cahill and McGaugh 1998) may depend on the induction of Fos and related genes.

Two aspects of our specific experimental design deserve further attention in future studies: the use of our home cage conditioning system and the specific time point chosen for analysis of Fos expression. With regard to home cage conditioning, our study was motivated by the idea that it is crucial to minimize baseline Fos expression in order to maximize sensitivity of Fos detection. However, it is possible that we have reduced the specificity of Fos detection, since we are not normalizing away the effects of handling. With regard to the specific time point chosen to detect Fos ( $1 \mathrm{~h}$ after training or testing), our rationale was that in variety of contexts in vivo and in vitro, Fos mRNA peaks about an hour after an increase in activity (Guzowski et al. 2001; Farivar et al. 2004; Pace et al. 2005; Schochet et al. 2005; Huff et al. 2006). However a recent study recently suggested in certain brain regions, such as nucleus accumbens (ACB), Fos mRNA may peak around $10 \mathrm{~min}$ following mild footshock (Xiu et al. 2014). While it is therefore possible that we have missed some brain regions by assessing Fos at $1 \mathrm{~h}$, we are not aware of specific evidence for any region that $1 \mathrm{~h}$ is too late to detect Fos expression.

The laboriousness of sectioning limited our " $n$ " and consequently increased the potential for type II statistical error (false negatives) in our study. Due to this limited statistical power, some of the many trends in our data that do not reach statistical significance may later prove to be real. One potential example relates to the observation that the shock-only group has greater (but not significantly greater) Fos induction than the fear conditioning group. If it proves to be significant, it is possible this greater induction could be a consequence of the unpredictability of painful stimuli, since unpredictability is a potent pain modulator that can influence neuronal activity throughout the brain (Carlsson et al. 2006; Oka et al. 2010; Schaap et al. 2013). Precise estimates of our statistical power and how it relates to the magnitude of expected changes are difficult to estimate, but more automated methods should soon enable type II error to be dramatically reduced.

\section{Materials and Methods}

\section{Animals}

All animal studies were approved by the Institutional Animal Care and Use Committee at Harvard University. P60 to P90 male C57BL/ 6 mice (Charles River) were used for this study and housed individually for $4 \mathrm{~d}$ prior to our behavioral procedures on a 12-h light-dark cycle. Behavioral studies were conducted during the light phase between 1:30 and 2:00 pm. For all of our behavior procedures, only mice that were part of the same conditioning or recall condition were trained or tested at the same time. All mice were sacrificed $1 \mathrm{~h}$ after our behavioral procedures except for our control group (Naïve). For our control group, mice were individually housed for the same period of time as our behavioral groups and were sacrificed at the same time.

\section{Home cage cued conditioning chambers}

Four home cage cued conditioning cages (HCCC) were designed and fabricated at the Harvard Medical School's Research Instrumentation Core. Each cage consists of a Techniplast Safe Seal IVC Blue Line cage bottom with a custom acrylic lid. Each cage contains a clear, acrylic insert containing a small enclosure $(13 \mathrm{~cm} \times 5 \mathrm{~cm} \times 5 \mathrm{~cm})$ and a food hopper. Mice housed in the cages have access to a $13 \mathrm{~cm} \times 24 \mathrm{~cm} \times 24.5 \mathrm{~cm}$ region in front of the insert to freely move. The floor of each cage is comprised of fifteen $3-\mathrm{mm}$ stainless steel dowels spaced by $8 \mathrm{~mm}$ oriented lengthwise along the cage. A custom-made connector connects these dowels to the output of a Med Associates Aversive Stimulator/Scrambler Module (env-414) which provides shocks during fear conditioning. The bar floor is elevated by $3.5 \mathrm{~cm}$ from the bottom of the cage. The space beneath the bar floor is filled with mouse bedding to absorb mouse urine. A water-delivery "nosepoke" is mounted to the front of each cage to provide water to housed mice. An IR-LED sensor mounted in each nosepoke triggers the release of a drop of water each time the nosepoke is entered by the mouse. Visaton BF-32-8 speakers mounted to the acrylic ceiling provided tones during conditioning. Shock delivery, water delivery, and tone generation is regulated by a custom PCB containing a Teensy 3.0 microcontroller programmed with custom firmware. Raspberry Pi model B computers mounted on each cage receive commands sent over a local network using Twisted-Python so that all four cages can be controlled in synchrony. Each Raspberry PI is equipped with a no-IR camera module that is mounted to the ceiling of each cage, allowing mice housed in the cages to be observed during and between behavioral sessions. Luxeon Rebel Deep Red (655 nm) LEDs mounted on the ceiling of each cage allow mice to be observed during the night.

\section{Behavioral procedures}

Behavioral studies were conducted during the light phase between 1:30 and 2:00 pm, and we did not evaluate their behavioral state of mice (asleep, awake) prior to conditioning. To determine the level of Fos induction in the brain caused by handling while using the conventional conditioning chamber apparatus, standard operant conditioning chambers at NeuroBehavior Laboratory at Harvard Medical School were used (Med Associates). Individually housed mice were handled and put into the conditioning chamber for $20 \mathrm{~min}$ for either $1 \mathrm{~d}$ and $4 \mathrm{~d}$ consecutively. After $20 \mathrm{~min}$ per day in the chamber, mice were returned to their home cage and were sacrificed $1 \mathrm{~h}$ after the end of the experiments, along with the control group that were not handled ( $n=3 /$ each group).

To evaluate the level of Fos induction in the brain that results from being housed in our HCCC, mice were individually housed in our HCCC for $72 \mathrm{~h}$ ( $n=4$ mice, each in a separate cage), then sacrificed. To determine the Fos induction in brain due to auditory conditioning (AC) in our HCCC, individually housed mice were put into our HCCC for $72 \mathrm{~h}$ and AC was performed $(n=4$ mice, each in a separate cage). The AC protocol consists of presenting seven repetitions of a CS $(80 \pm 5 \mathrm{~dB}, 6 \mathrm{kHz}, 10 \mathrm{sec})$ terminating with the US (1-sec footshock, $0.5 \mathrm{~mA} \mathrm{DC}$; inter-trial interval: $20-180 \mathrm{sec})$. The mice were sacrificed $1 \mathrm{~h}$ after the AC.

To assess recall conventionally, mice were trained in our HCCC with same AC protocol (see above), and for familiar tone control, the mice were trained with the same AC protocol but without US ( $n=8$ / each group). Twenty-four hours after the conditioning, the mice were returned to the facility home cages. Thirty days after the training, the mice were put back into our HCCC with a white plastic floor and $7 \mathrm{~min}$ later the mice were presented with seven repetition of $\mathrm{CS}+(80 \pm 5 \mathrm{~dB}, 6 \mathrm{kHz}, 10 \mathrm{~s}$; intertrial interval: $20-180 \mathrm{sec})$. The video were analyzed using Etho Vision software and the result is described in Supplemental Figure 11 and Gruene et al. (2016).

To determine the activated brain regions during fear learning, mice were assigned to separate groups (Context-only, Tone-only, Shock-only, and AC) and trained accordingly in our HCCC following $72 \mathrm{~h}$ inside the cages. For Context group, the mice were sacrificed after spending $72 \mathrm{~h}$ inside our cage. For Tone group, the mice were presented with seven repetitions of a CS $(80 \pm 5 \mathrm{~dB}, 6 \mathrm{kHZ}, 10 \mathrm{sec}$; inter-trial interval: $20-180 \mathrm{sec})$. For Shock groups, the mice were presented with seven repetitions of a US (1-sec footshock, $0.5 \mathrm{~mA} \mathrm{DC}$; inter-trial interval: 20-180 $\mathrm{sec})$. For AC group, the mice were presented with the same CS terminating with same US seven times (see above). All mice were sacrificed $1 \mathrm{~h}$ after the end of the experiments ( $n=4$ /each group).

To identify activated brain regions during recall tests, mice were assigned to separate groups: $1 \mathrm{~d}$ recall familiar tone (1DRFT), $1 \mathrm{~d}$ recall fear conditioned (1DRFC), 1 mo recall familiar tone (1MRFT), and 1 mo recall fear conditioned (1MRFC). For 
1DRFT, after spending $72 \mathrm{~h}$ inside our cage, the mice were presented with seven repetitions of a tone $(80 \pm 5 \mathrm{~dB}, 6 \mathrm{kHz}, 10 \mathrm{sec})$, and the mice stayed in our cage for $24 \mathrm{~h}$ before being re-presented with seven repetitions of the same tone. For $1 D R F C$, after spending $72 \mathrm{~h}$ inside our cage, the mice were conditioned using the AC protocol (see above) and the mice stayed in our cage for $24 \mathrm{~h}$ before the same seven CSs were re-presented. For 1MRFT, after spending 72 $\mathrm{h}$ inside our cage, the mice were presented with seven repetitions of a tone $(80 \pm 5 \mathrm{~dB}, 6 \mathrm{kHz}, 10 \mathrm{sec})$, and the mice stayed inside our cage $24 \mathrm{~h}$ before transferring to their facility home cage. After 27 $\mathrm{d}$, the mice were once again transferred to our HCCC, and the mice were re-presented with the same seven tones after spending $72 \mathrm{~h}$ inside our cage. For 1MRFC, after spending $72 \mathrm{~h}$ inside our cage, the mice were conditioned using the AC protocol (see above) and the mice stayed inside our cage $24 \mathrm{~h}$ before transferring to their home cage. After $27 \mathrm{~d}$, the mice were once again transferred to our HCCC and the mice were presented with the same seven CSs after spending $72 \mathrm{~h}$ inside our cage. All mice were sacrificed $1 \mathrm{~h}$ after the end of the experiments ( $n=4$ /each group).

\section{Tissue preparation}

Mice were rapidly sacrificed with carbon dioxide and quickly decapitated. The heads were covered in ice while the brains were being dissected out and their brains were rapidly frozen using dry ice in methylbutane. From the moment carbon dioxide was applied to the freezing of the brains, the whole procedure (four brains/procedure) took $<20 \mathrm{~min}$.

All the brains were stored at $-80^{\circ} \mathrm{C}$ until the cryosectioning. Although 4 brains were collected for each group, only three brains per group were randomly selected to be cryo-sectioned. Coronal sections $(20 \mu \mathrm{m})$ were cut on a cryostat and slides stored at $-20^{\circ} \mathrm{C}$ until further use.

\section{Fluorescent in situ hybridization}

Nonradioactive, digoxigenin (DIG)-labeled cRNA probes with either sense or antisense orientation were synthesized by in vitro transcription using DIG labeling mix (Roche) according to the recommendations of the manufacturer. Probes were synthesized from cDNA clones encoding Fos purchased from Dharmacon (MMM1013-202760329). For fluorescent in situ hybridization (FISH), all solutions were prepared using RNase-free reagents and diethylpyrocarbonate (DEPC)-treated double deionzide water $\left(\mathrm{ddH}_{2} \mathrm{O}\right)$. All the brain sections were processed as described previously (Cho et al. 2016).

\section{Microscopy and image analysis}

All fluorescent images were acquired with a $10 \times$ objective lens using an Olympus VS120 Whole slide scanner at the Harvard Neurobiology Imaging Facility (NS072030). For whole-brain analysis, brain sections at each $120 \mu \mathrm{m}$ interval (every sixth section) were imaged.

\section{Cell detection}

Cell detection was done using fully convolutional neural network (FCN), implemented with the Caffe deep learning framework (http://caffe.berkeleyvision.org/). The FCN was trained on 139 $500 \times 500$ pixel images, which were manually annotated by an expert biologist. The network was trained over 300,000 iterations, where each iteration consisted of 256 randomly selected output pixels, and their corresponding input windows $(161 \times 161$ pixels $)$ from within the training images. Training was performed on a GTX 760 over 3 d. Individual cells are identified from the output of the FCN by applying a Gaussian filter $(\sigma)$, a binary threshold $(t)$, morphological opening $(r)$ and finally a watershedding algorithm. The optimal parameters for this post-processing step $(\sigma, t, r)$ were determined by optimizing the $F$-score of the detected cells calculated for 46 testing images that were annotated by the same biologist. Cell detection accuracy was evaluated by comparing detected cells in 46 cross-validation images to ground truth mark- ups produced by three expert biologists via $F$-scores and correlation of cell counts (Fig. 1E; Supplemental Fig. 1).

\section{Image registration}

Images were registered to the Allen Brain Atlas (ABA; http://www. brain-map.org/) using a custom image registration pipeline built on the Insight-Toolkit (http://www.itk.org/). Before registration to the ABA, active contour segmentation was used to identify the brain section within each image, and all nonsection pixels were zeroed. The images were then resampled to the scale of the reference atlas. Image registration consisted of an affine transform and a b-spline transform, both of which were optimized against the Allen Reference Atlas using negated mutual information as the error metric. Following registration, the registered labels were manually verified using a custom MATLAB tool that allows for side-by-side comparison of the registered labels and the target image. Improperly registered regions of images were flagged so that they were not considered during analysis.

\section{Selection of regions for analysis (Fig. 4)}

The final list of brain regions selected for analysis was chosen based on the finest-grain subregions that consistently passed registration QC. Primary and secondary cortices were pooled because we did not observe significant differences within major cortical regions (Supplemental Fig. 7). The pons and medulla were combined as the hindbrain, and all sub-regions of the cerebellum were consolidated.

\section{Statistical analysis}

Statistical analysis was performed in python using the scipy.stats module. Regression analysis (Fig. 1E; Supplemental Fig. 10) was done using linear least squares analysis. Fos ${ }^{+}$densities were compared using Welch's $t$-test and corrected for multiple comparisons using the Benjamini-Hochberg correction (Supplemental Fig. 4). Amygdalar induction was assessed by treating the LA, BLA, BMA, and CEA as a single brain region, then comparing $\mathrm{Fos}^{+}$densities using Welch's $t$-test. Brain-wide Fos induction was compared between experimental conditions by comparing the distributions of regionwise $P$-values (obtained via Welch's $t$-test) to a null, uniform distribution using a Kolmogorov-Smirnov (KS) test (Supplemental Fig. 8). The resulting $P$-values were corrected for multiple comparisons using a Bonferroni correction for 28 intercondition comparisons. For conventional analysis of freezing data between fear conditioned and familiar tone groups trained in our HCCC, statistical analysis was performed using commercial software (GraphPad Prism; GraphPad Software, Inc.).

\section{Behavior analysis of home cage conditioning}

Dashing behavior was scored manually, where a dash consisted of movement over a distance greater than a body length, or a rotation of $\sim 180^{\circ}$ in under a second. Total movement traveled within the cage was measured using custom MATLAB scripts. The mouse's position in the cage was designated as the centroid of the mouse-containing region in each frame, determined through binary thresholding and morphological filtering. Measurement noise was reduced by averaging each centroid with the two preceding and following it, eliminating small high-frequency jitters produced by the identification algorithm while preserving the overall structure of the mouse's movement. For recall behavior analysis, a blinded experimenter manually determined the reaction of the mice when tone was presented. Any changes in either the breathing pattern and/or sudden head or body movements were marked as yes and marked no if no noticeable changes in breathing or movements were observed.

\section{Competing interest statement}

The authors declare no competing financial interests. 


\section{Acknowledgments}

We thank Pavel Gorelik and Ofer Mazor at the HMS Research Instrumentation Core Facility for assistance in home cage classical conditioning chamber design and fabrication; Michelle Ocana and the Harvard Neural Imaging Center (NS072030) for assistance with imaging; Pavel Osten and Kannan Umadevi Venkataraju for assistance with cell detection; David Harmin for assistance with statistical analysis; and Barbara Caldarone and the Neurobehavior core for assistance with fear conditioning. We thank Kelsey Tyssowski, Nicholas DeStefino, Sarah Chang, Samantha Sarli and Ben S. Huang for comments on the manuscript. We thank Emma Nash and Samantha Sarli for manually counting $\mathrm{Fos}^{+}$neurons for CNN validation. This work was funded by R01 MH101528-01, BCH IDDRC 1U54HD090255, and MH104785-01. J.-H.C. is supported by a postdoctoral fellowship from the Canadian Institute of Health Research.

Author contributions: J.-H.C., S.D.R., and J.M.G. designed the experiments; J.-H.C. performed histological and behavioral assays. J.-H.C. and S.D.R. performed the imaging. S.D.R. created the home cage conditioning chambers and wrote the cell detection and image registration software. S.D.R. performed statistical analysis with help from J.-H.C. and J.M.G. J.M.G. wrote the manuscript with help from J.-H.C. and S.D.R.

\section{Appendix A: Region name table}

\begin{tabular}{|c|c|c|c|c|c|c|c|}
\hline \multicolumn{4}{|c|}{ We thank Pavel Gorelik and Ofer Mazor at the HMS Research } & Acronym & Name & Acronym & Name \\
\hline \multicolumn{4}{|c|}{$\begin{array}{l}\text { Instrumentation Core Facility for assistance in home cage classical } \\
\text { conditioning chamber design and fabrication; Michelle Ocana }\end{array}$} & $\overline{\mathrm{ECT}}$ & Ectorhinal area & PVR & Periventricular region \\
\hline \multicolumn{4}{|c|}{$\begin{array}{l}\text { and the Harvard Neural Imaging Center (NS072030) for assistance } \\
\text { with imaging; Pavel Osten and Kannan Umadevi Venkataraju }\end{array}$} & ENT & Entorhinal area & PVT & Paraventricular nucleus \\
\hline \multicolumn{4}{|c|}{$\begin{array}{l}\text { for assistance with cell detection; David Harmin for assistance } \\
\text { with statistical analysis; and Barbara Caldarone and the Neurobe- } \\
\text { havior core for assistance with fear conditioning. We thank Kelsey }\end{array}$} & EP & Endopiriform nucleus & PVi & $\begin{array}{l}\text { of the thalamus } \\
\text { Periventricular } \\
\text { hypothalamic nucleus, } \\
\text { intermediate part }\end{array}$ \\
\hline \multicolumn{4}{|c|}{ Tyssowski, Nicholas DeStefino, Sarah Chang, Samantha Sarli and } & EW & $\begin{array}{l}\text { Edinger-Westphal } \\
\text { nucleus }\end{array}$ & $\mathrm{RE}$ & Nucleus of reunions \\
\hline \multirow{2}{*}{\multicolumn{4}{|c|}{$\begin{array}{l}\text { Nash and Samantha Sarli for manually counting Fos neurons for } \\
\text { CNN validation. This work was funded by R01 MH101528-01, }\end{array}$}} & FS & Fundus of striatum & $\mathrm{RH}$ & Rhomboid nucleus \\
\hline & & & & GPe & $\begin{array}{l}\text { Globus pallidus, } \\
\text { external segment }\end{array}$ & $\mathrm{RL}$ & $\begin{array}{l}\text { Rostral linear nucleus } \\
\text { raphe }\end{array}$ \\
\hline \multirow{2}{*}{\multicolumn{4}{|c|}{$\begin{array}{l}\text { BCH IDDRC } 1 \text { U54HD090255, and MH104785-01. J.-H.C. is sup- } \\
\text { ported by a postdoctoral fellowship from the Canadian Institute } \\
\text { of Health Research. }\end{array}$}} & GPi & $\begin{array}{l}\text { Globus pallidus, } \\
\text { internal segment }\end{array}$ & $\mathrm{RN}$ & Red nucleus \\
\hline & & & & GU & Gustatory areas & RSP & Retrosplenial area \\
\hline \multirow{3}{*}{\multicolumn{4}{|c|}{$\begin{array}{l}\text { Author contributions: J.-H.C., S.D.R., and J.M.G. designed the } \\
\text { experiments; J.-H.C. performed histological and behavioral as- } \\
\text { says. J.-H.C. and S.D.R. performed the imaging. S.D.R. created } \\
\text { the home cage conditioning chambers and wrote the cell detec- } \\
\text { tion and image registration software. S.D.R. performed statistical } \\
\text { analysis with help from J.-H.C. and J.M.G. J.M.G. wrote the man- } \\
\text { uscript with help from J.-H.C. and S.D.R. }\end{array}$}} & $\mathrm{HB}$ & Hindbrain & RT & $\begin{array}{l}\text { Reticular nucleus of the } \\
\text { thalamus }\end{array}$ \\
\hline & & & & IA & $\begin{array}{l}\text { Intercalated amygdalar } \\
\text { nucleus }\end{array}$ & $\mathrm{SCm}$ & $\begin{array}{l}\text { Superior colliculus, } \\
\text { motor related }\end{array}$ \\
\hline & & & & IAD & $\begin{array}{l}\text { Interanterodorsal } \\
\text { nucleus of the } \\
\text { thalamus }\end{array}$ & SCs & $\begin{array}{l}\text { Superior colliculus, } \\
\text { sensory related }\end{array}$ \\
\hline \multicolumn{4}{|c|}{ Appendix A: Region name table } & IAM & $\begin{array}{l}\text { Interanteromedial } \\
\text { nucleus of the } \\
\text { thalamus }\end{array}$ & SGN & Suprageniculate nucleus \\
\hline Acronym & Name & Acronym & Name & $\mathrm{ICe}$ & $\begin{array}{l}\text { Inferior colliculus, } \\
\text { external nucleus }\end{array}$ & $\mathrm{SH}$ & $\begin{array}{l}\text { Septohippocampal } \\
\text { nucleus }\end{array}$ \\
\hline \multirow[t]{2}{*}{ AAA } & \multirow{2}{*}{$\begin{array}{l}\text { Anterior amygdalar } \\
\text { area }\end{array}$} & \multirow[t]{2}{*}{$\mathrm{MO}$} & \multirow[t]{2}{*}{ Somatomotor areas } & IG & Induseum griseum & $\mathrm{SI}$ & Substantia innominata \\
\hline & & & & IGL & Intergeniculate leaflet & SMT & Submedial nucleus of \\
\hline ACA & Anterior cingulate area & MPN & Medial preoptic nucleus & & of the lateral & & the thalamus \\
\hline$A C B$ & Nucleus accumbens & MPT & Medial pretectal area & & geniculate complex & & \\
\hline$A D$ & Anterodorsal nucleus & MSC & Medial septal complex & III & Oculomotor nucleus & SNc & Substantia nigra, \\
\hline $\mathrm{AHN}$ & $\begin{array}{l}\text { Anterior hypothalamic } \\
\text { nucleus }\end{array}$ & NB & $\begin{array}{l}\text { Nucleus of the } \\
\text { brachium of the } \\
\text { inferior colliculus }\end{array}$ & ILA & Infralimbic area & $\mathrm{SNr}$ & $\begin{array}{l}\text { compact part } \\
\text { Substantia nigra, } \\
\text { reticular part }\end{array}$ \\
\hline $\mathrm{Al}$ & Agranular insular area & NOT & $\begin{array}{l}\text { Nucleus of the optic } \\
\text { tract }\end{array}$ & IMD & $\begin{array}{l}\text { Intermediodorsal } \\
\text { nucleus of the }\end{array}$ & SO & Supraoptic nucleus \\
\hline AMd & $\begin{array}{l}\text { Anteromedial nucleus, } \\
\text { dorsal part }\end{array}$ & NPC & $\begin{array}{l}\text { Nucleus of the posterior } \\
\text { commissure }\end{array}$ & LA & $\begin{array}{l}\text { thalamus } \\
\text { Lateral amygdalar } \\
\text { nucleus }\end{array}$ & SPF & $\begin{array}{l}\text { Subparafascicular } \\
\text { nucleus }\end{array}$ \\
\hline AMv & $\begin{array}{l}\text { Anteromedial nucleus, } \\
\text { ventral part }\end{array}$ & OLF & Olfactory areas & LD & $\begin{array}{l}\text { nucleus } \\
\text { Lateral dorsal nucleus }\end{array}$ & SS & $\begin{array}{l}\text { nucleus } \\
\text { Somatosensory areas }\end{array}$ \\
\hline APN & $\begin{array}{l}\text { Anterior pretectal } \\
\text { nucleus }\end{array}$ & OP & $\begin{array}{l}\text { Olivary pretectal } \\
\text { nucleus }\end{array}$ & \multirow[t]{2}{*}{ LGd } & $\begin{array}{l}\text { of thalamus } \\
\text { Dorsal part of the }\end{array}$ & SUB & Subiculum \\
\hline $\mathrm{ARH}$ & $\begin{array}{l}\text { Arcuate hypothalamic } \\
\text { nucleus }\end{array}$ & ORB & Orbital area & & $\begin{array}{l}\text { lateral geniculate } \\
\text { complex }\end{array}$ & & \\
\hline \multirow{2}{*}{$\begin{array}{l}\text { AUD } \\
\text { AV }\end{array}$} & Auditory areas & OT & Olfactory tubercle & \multirow[t]{2}{*}{ LGv } & \multirow{2}{*}{$\begin{array}{l}\text { Ventral part of the } \\
\text { lateral geniculate } \\
\text { complex }\end{array}$} & \multirow[t]{2}{*}{ SUM } & Supramammillary \\
\hline & $\begin{array}{l}\text { Anteroventral nucleus } \\
\text { of thalamus }\end{array}$ & PA & $\begin{array}{l}\text { Posterior amygdalar } \\
\text { nucleus }\end{array}$ & & & & nucleus \\
\hline BLA & $\begin{array}{l}\text { Basolateral amygdalar } \\
\text { nucleus }\end{array}$ & PAG & Periaqueductal gray & $\mathrm{LH}$ & Lateral habenula & TEa & $\begin{array}{l}\text { Temporal association } \\
\text { areas }\end{array}$ \\
\hline BMA & $\begin{array}{l}\text { Basomedial amygdalar } \\
\text { nucleus }\end{array}$ & $\mathrm{PCN}$ & Paracentral nucleus & LHA & $\begin{array}{l}\text { Lateral hypothalamic } \\
\text { area }\end{array}$ & $\mathrm{TMv}$ & $\begin{array}{l}\text { Tuberomammillary } \\
\text { nucleus, ventral part }\end{array}$ \\
\hline BST & $\begin{array}{l}\text { Bed nuclei of the stria } \\
\text { terminalis }\end{array}$ & PERI & Perirhinal area & LM & $\begin{array}{l}\text { Lateral mammillary } \\
\text { nucleus }\end{array}$ & TRS & $\begin{array}{l}\text { Triangular nucleus of } \\
\text { septum }\end{array}$ \\
\hline CA1 & Field CA1 & $\mathrm{PH}$ & $\begin{array}{l}\text { Posterior hypothalamic } \\
\text { nucleus }\end{array}$ & LP & $\begin{array}{l}\text { Lateral posterior } \\
\text { nucleus of the }\end{array}$ & TU & Tuberal nucleus \\
\hline CA2 & Field CA2 & PL & Prelimbic area & & & & \\
\hline CA3 & Field CA3 & PO & $\begin{array}{l}\text { Posterior complex of } \\
\text { the thalamus }\end{array}$ & LPO & Lateral preoptic area & VAL & $\begin{array}{l}\text { Ventral anterior-lateral } \\
\text { complex of the }\end{array}$ \\
\hline CBX & Cerebellar cortex & POL & $\begin{array}{l}\text { Posterior limiting } \\
\text { nucleus of the }\end{array}$ & LS & Lateral septal nucleus & VIS & $\begin{array}{l}\text { thalamus } \\
\text { Visual areas }\end{array}$ \\
\hline & & & thalamus & LT & Lateral terminal & VISC & Visceral area \\
\hline CEA & $\begin{array}{l}\text { Central amygdalar } \\
\text { nucleus }\end{array}$ & POST & Postsubiculum & & $\begin{array}{l}\text { nucleus of the } \\
\text { accessory optic tract }\end{array}$ & & \\
\hline CLA & Claustrum & PP & Peripeduncular nucleus & $\mathrm{MA}$ & Magnocellular nucleus & VM & Ventral medial nucleus \\
\hline $\mathrm{CLI}$ & $\begin{array}{l}\text { Central linear nucleus } \\
\text { raphe }\end{array}$ & PPT & $\begin{array}{l}\text { Posterior pretectal } \\
\text { nucleus }\end{array}$ & MD & Mediodorsal nucleus of & VMH & $\begin{array}{l}\text { of the thalamus } \\
\text { Ventromedial }\end{array}$ \\
\hline CM & $\begin{array}{l}\text { Central medial nucleus } \\
\text { of the thalamus }\end{array}$ & PRE & Presubiculum & MEA & $\begin{array}{l}\text { thalamus } \\
\text { Medial amygdalar }\end{array}$ & VP & $\begin{array}{l}\text { hypothalamic nucleus } \\
\text { Ventral posterior }\end{array}$ \\
\hline CP & Caudoputamen & PTLp & $\begin{array}{l}\text { Posterior parietal } \\
\text { association areas }\end{array}$ & & nucleus & & $\begin{array}{l}\text { complex of the } \\
\text { thalamus }\end{array}$ \\
\hline DG & Dentate gyrus & PVH & $\begin{array}{l}\text { Paraventricular } \\
\text { hypothalamic nucleus }\end{array}$ & & $\begin{array}{l}\text { Medial geniculate } \\
\text { complex }\end{array}$ & VTA & Ventral tegmental area \\
\hline & & & & $\mathrm{MH}$ & Medial habenula & & \\
\hline
\end{tabular}

Appendix A Continued 


\section{References}

Anthony TE, Dee N, Bernard A, Lerchner W, Heintz N, Anderson DJ. 2014. Control of stress-induced persistent anxiety by an extra-amygdala septohypothalamic circuit. Cell 156: $522-536$.

Barth AL. 2007. Visualizing circuits and systems using transgenic reporters of neural activity. Curr Opin Neurobiol 17: 567-571.

Beaver CJ, Mitchell DE, Robertson HA. 1993. Immunohistochemical study of the pattern of rapid expression of $\mathrm{C}$-fos protein in the visual cortex of dark-reared kittens following initial exposure to light. J Comp Neurol 333: $469-484$.

Cahill L, McGaugh JL. 1998. Mechanisms of emotional arousal and lasting declarative memory. Trends Neurosci 21: 294-299.

Cai DJ, Aharoni D, Shuman T, Shobe J, Biane J, Song W, Wei B, Veshkini M, La-Vu M, Lou J, et al. 2016. A shared neural ensemble links distinct contextual memories encoded close in time. Nature 534: 115-118.

Campeau S, Watson SJ. 1997. Neuroendocrine and behavioral responses and brain pattern of c-fos induction associated with audiogenic stress. J Neuroendocrinol 9: 577-588.

Campeau S, Hayward MD, Hope BT, Rosen JB, Nestler EJ, Davis M. 1991. Induction of the c-fos proto-oncogene in rat amygdala during unconditioned and conditioned fear. Brain Res 565: 349-352.

Carlsson K, Andersson J, Petrovic P, Petersson KM, Ohman A, Ingvar M. 2006. Predictability modulates the affective and sensory-discriminative neural processing of pain. NeuroImage 32: 1804-1814.

Cho JH, Huang BS, Gray JM. 2016. RNA sequencing from neural ensembles activated during fear conditioning in the mouse temporal association cortex. Sci Rep 6: 31753.

Cowansage KK, Shuman T, Dillingham BC, Chang A, Golshani P, Mayford M. 2014. Direct reactivation of a coherent neocortical memory of context. Neuron 84: 432-441.

Cullinan WE, Herman JP, Battaglia DF, Akil H, Watson SJ. 1995. Pattern and time course of immediate early gene expression in rat brain following acute stress. Neuroscience 64: 477-505.

Denny CA, Kheirbek MA, Alba EL, Tanaka KF, Brachman RA, Laughman KB, Tomm NK, Turi GF, Losonczy A, Hen R. 2014. Hippocampal memory traces are differentially modulated by experience, time, and adult neurogenesis. Neuron 83: 189-201.

Farivar R, Zangenehpour S, Chaudhuri A. 2004. Cellular-resolution activity mapping of the brain using immediate-early gene expression. Front Biosci 9: 104-109.

Frankland PW, Bontempi B. 2005. The organization of recent and remote memories. Nat Rev Neurosci 6: 119-130.

Garner AR, Rowland DC, Hwang SY, Baumgaertel K, Roth BL, Kentros C, Mayford M. 2012. Generation of a synthetic memory trace. Science 335: 1513-1516.

Gouty-Colomer LA, Hosseini B, Marcelo IM, Schreiber J, Slump DE, Yamaguchi S, Houweling AR, Jaarsma D, Elgersma Y, Kushner SA. 2015. Arc expression identifies the lateral amygdala fear memory trace. Mol Psychiatry 21: 364-375.

Greenberg ME, Ziff EB, Greene LA. 1986. Stimulation of neuronal acetylcholine receptors induces rapid gene transcription. Science 234: 80-83.

Gruene T, Flick K, Rendall S, Cho JH, Gray J, Shansky R. 2016. Activity-dependent structural plasticity after aversive experiences in amygdala and auditory cortex pyramidal neurons. Neuroscience 328: 157-164.

Guzowski JF, McNaughton BL, Barnes CA, Worley PF. 1999. Environment-specific expression of the immediate-early gene Arc in hippocampal neuronal ensembles. Nat Neurosci 2: 1120-1124.

Guzowski JF, Setlow B, Wagner EK, McGaugh JL. 2001. Experience-dependent gene expression in the rat hippocampus after spatial learning: a comparison of the immediate-early genes Arc, c-fos, and zif268. J Neurosci 21: 5089-5098.

Han JH, Yiu AP, Cole CJ, Hsiang HL, Neve RL, Josselyn SA. 2008. Increasing $\mathrm{CREB}$ in the auditory thalamus enhances memory and generalization of auditory conditioned fear. Learn Mem 15: 443-453.

Huff NC, Frank M, Wright-Hardesty K, Sprunger D, Matus-Amat P, Higgins E, Rudy JW. 2006. Amygdala regulation of immediate-early gene expression in the hippocampus induced by contextual fear conditioning. J Neurosci 26: 1616-1623.

Johansen JP, Cain CK, Ostroff LE, LeDoux JE. 2011. Molecular mechanisms of fear learning and memory. Cell 147: 509-524.

Josselyn SA, Köhler S, Frankland PW. 2015. Finding the engram. Nat Rev Neurosci 16: $521-534$.

Kawashima T, Okuno H, Bito H. 2014. A new era for functional labeling of neurons: activity-dependent promoters have come of age. Front Neural Circuits 8: 37.

Kim JJ, Fanselow MS. 1992. Modality-specific retrograde amnesia of fear. Science 256: 675-677.

Kim Y, Venkataraju KU, Pradhan K, Mende C, Taranda J, Turaga SC, Arganda-Carreras I, Ng L, Hawrylycz MJ, Rockland KS, et al. 2015.
Mapping social behavior-induced brain activation at cellular resolution in the mouse. Cell Rep 10: 292-305.

Kwon JT, Jhang J, Kim HS, Lee S, Han JH. 2012. Brain region-specific activity patterns after recent or remote memory retrieval of auditory conditioned fear. Learn Mem 19: 487-494.

Lamprecht R, Dracheva S, Assoun S, LeDoux JE. 2009. Fear conditioning induces distinct patterns of gene expression in lateral amygdala. Genes Brain Behav 8: $735-743$.

Lang PJ, Bradley MM, Fitzsimmons JR, Cuthbert BN, Scott JD, Moulder B, Nangia V. 1998. Emotional arousal and activation of the visual cortex: an fMRI analysis. Psychophysiology 35: 199-210.

Lashley KS. 1950. Psychological mechanisms in animal behavior: society of experimental biology symposium, No. 4. Cambridge Univ. Press, Cambridge, UK.

Letzkus JJ, Wolff SB, Meyer EM, Tovote P, Courtin J, Herry C, Lüthi A. 2011. A disinhibitory microcircuit for associative fear learning in the auditory cortex. Nature 480: 331-335.

Levita L, Dalley JW, Robbins TW. 2002. Nucleus accumbens dopamine and learned fear revisited: a review and some new findings. Behav Brain Res 137: $115-127$.

Lindquist KA, Wager TD, Kober H, Bliss-Moreau E, Barrett LF. 2012. The brain basis of emotion: a meta-analytic review. Behav Brain Sci 35: $121-143$.

Liu X, Ramirez S, Pang PT, Puryear CB, Govindarajan A, Deisseroth K, Tonegawa S. 2012. Optogenetic stimulation of a hippocampal engram activates fear memory recall. Nature 484: 381-385.

Maren S. 1999. Neurotoxic or electrolytic lesions of the ventral subiculum produce deficits in the acquisition and expression of Pavlovian fear conditioning in rats. Behav Neurosci 113: 283-290.

Mayford M, Reijmers L. 2015. Exploring memory representations with activity-based genetics. Cold Spring Harb Perspect Biol 8: a021832.

Melzer P, Steiner H. 1997. Stimulus-dependent expression of immediate-early genes in rat somatosensory cortex. J Comp Neurol 380: $145-153$.

Morgan JI, Cohen DR, Hempstead JL, Curran T. 1987. Mapping patterns of c-fos expression in the central nervous system after seizure. Science 237: 192-197.

Morrison DJ, Rashid AJ, Yiu AP, Yan C, Frankland PW, Josselyn SA. 2016. Parvalbumin interneurons constrain the size of the lateral amygdala engram. Neurobiol Learn Mem 135: 91-99.

Oh SW, Harris JA, Ng L, Winslow B, Cain N, Mihalas S, Wang Q, Lau C, Kuan L, Henry AM, et al. 2014. A mesoscale connectome of the mouse brain. Nature 508: 207-214.

Oka S, Chapman CR, Kim B, Shimizu O, Noma N, Takeichi O, Imamura Y, Oi Y. 2010. Predictability of painful stimulation modulates subjective and physiological responses. J Pain 11: 239-246.

O'Mara S. 2005. The subiculum: what it does, what it might do, and what neuroanatomy has yet to tell us. J Anat 207: 271-282.

O'Mara SM, Sanchez-Vives MV, Brotons-Mas JR, O'Hare E. 2009. Roles for the subiculum in spatial information processing, memory, motivation and the temporal control of behaviour. Prog Neuropsychopharmacol Biol Psychiatry 33: 782-790.

Pace TWW, Gaylord R, Topczewski F, Girotti M, Rubin B, Spencer RL. 2005. Immediate-early gene induction in hippocampus and cortex as a result of novel experience is not directly related to the stressfulness of that experience. Eur J Neurosci 22: 1679-1690.

Peter M, Scheuch H, Burkard TR, Tinter J, Wernle T, Rumpel S. 2012. Induction of immediate early genes in the mouse auditory cortex after auditory cued fear conditioning to complex sounds. Genes Brain Behav 11: $314-324$.

Pezzone MA, Lee WS, Hoffman GE, Rabin BS. 1992. Induction of c-fos immunoreactivity in the rat forebrain by conditioned and unconditioned aversive stimuli. Brain Res 597: 41-50.

Pezzone MA, Lee WS, Hoffman GE, Pezzone KM, Rabin BS. 1993. Activation of brainstem catecholaminergic neurons by conditioned and unconditioned aversive stimuli as revealed by c-fos immunoreactivity. Brain Res 608: 310-318.

Phillips RG, LeDoux JE. 1992. Differential contribution of amygdala and hippocampus to cued and contextual fear conditioning. Behav Neurosci 106: $274-285$.

Radulovic J, Kammermeier J, Spiess J. 1998. Relationship between fos production and classical fear conditioning: effects of novelty, laten inhibition, and unconditioned stimulus preexposure. J Neurosci 18: $7452-7461$

Rashid AJ, Yan C, Mercaldo V, Hsiang HL, Park S, Cole CJ, De Cristofaro A, Yu J, Ramakrishnan C, Lee SY, et al. 2016. Competition between engrams influences fear memory formation and recall. Science 353: $383-387$.

Renier N, Wu Z, Simon DJ, Yang J, Ariel P, Tessier-Lavigne M. 2014. iDISCO a simple, rapid method to immunolabel large tissue samples for volume imaging. Cell 159: 896-910. 
Renier N, Adams EL, Kirst C, Wu Z, Azevedo R, Kohl J, Autry AE, Kadiri L, Umadevi Venkataraju K, Zhou Y, et al. 2016. Mapping of brain activity by automated volume analysis of immediate early genes. Cell 165: $1789-1802$.

Rosen KM, McCormack MA, Villa-Komaroff L, Mower GD. 1992. Brief visual experience induces immediate early gene expression in the cat visual cortex. Proc Natl Acad Sci 89: 5437-5441.

Sacco T, Sacchetti B. 2010. Role of secondary sensory cortices in emotional memory storage and retrieval in rats. Science 329: 649-656.

Schaap MWH, van Oostrom H, Doornenbal A, Baars AM, Arndt SS, Hellebrekers LJ. 2013. Predictability of painful stimulation modulates the somatosensory-evoked potential in the rat. PLoS One 8: e61487.

Schochet TL, Kelley AE, Landry CF. 2005. Differential expression of arc mRNA and other plasticity-related genes induced by nicotine in adolescent rat forebrain. Neuroscience 135: 285-297.

Selden NR, Everitt BJ, Jarrard LE, Robbins TW. 1991. Complementary roles for the amygdala and hippocampus in aversive conditioning to explicit and contextual cues. Neuroscience 42: 335-350.

Senba E, Ueyama T. 1997. Stress-induced expression of immediate early genes in the brain and peripheral organs of the rat. Neurosci Res 29: 183-207.

Smith SM, Vale WW. 2006. The role of the hypothalamic-pituitary-adrenal axis in neuroendocrine responses to stress. Dialogues Clin Neurosci 8: $383-395$.

Smith MA, Banerjee S, Gold PW, Glowa J. 1992. Induction of c-fos mRNA in rat brain by conditioned and unconditioned stressors. Brain Res 578: $135-141$.

Tanaka KZ, Pevzner A, Hamidi AB, Nakazawa Y, Graham J, Wiltgen BJ. 2014. Cortical representations are reinstated by the hippocampus during memory retrieval. Neuron 84: $347-354$.
Tischmeyer W, Grimm R. 1999. Activation of immediate early genes and memory formation. Cell Mol Life Sci 55: 564-574.

Tovote P, Fadok JP, Lüthi A. 2015. Neuronal circuits for fear and anxiety. Nat Rev Neurosci 16: 317-331.

Vertes RP, Linley SB, Hoover WB. 2015. Limbic circuitry of the midline thalamus. Neurosci Biobehav Rev 54: 89-107.

Vousden DA, Epp J, Okuno H, Nieman BJ, van Eede M, Dazai J, Ragan T, Bito H, Frankland PW, Lerch JP, et al. 2015. Whole-brain mapping of behaviourally induced neural activation in mice. Brain Struct Funct 220: 2043-2057.

West AE, Greenberg ME. 2011. Neuronal activity-regulated gene transcription in synapse development and cognitive function. Cold Spring Harb Perspect Biol 3: a005744.

West AE, Griffith EC, Greenberg ME. 2002. Regulation of transcription factors by neuronal activity. Nat Rev Neurosci 3: 921-931.

Wheeler AL, Teixeira CM, Wang AH, Xiong X, Kovacevic N, Lerch JP, McIntosh AR, Parkinson J, Frankland PW. 2013. Identification of a functional connectome for long-term fear memory in mice. PLoS Comput Biol 9: e1002853.

Xiu J, Zhang Q, Zhou T, Zhou TT, Chen Y, Hu H. 2014. Visualizing an emotional valence map in the limbic forebrain by TAI-FISH. Nat Neurosci 17: 1552-1559.

Yen CT, Lu PL. 2013. Thalamus and pain. Acta Anaesthesiol Taiwan 51: 73-80.

Received October 14, 2016; accepted in revised form February 23, 2017. 


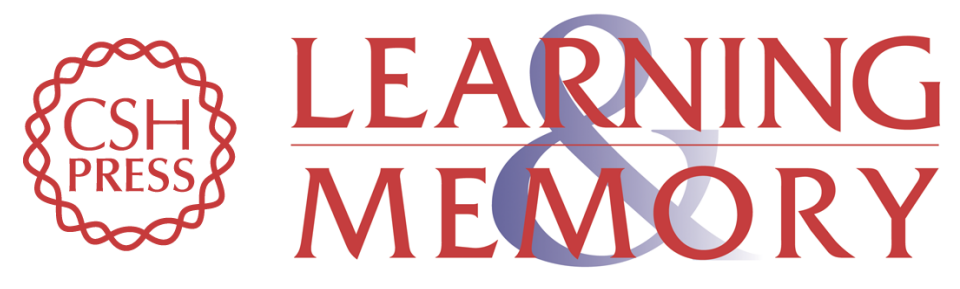

\section{Brain-wide maps of Fos expression during fear learning and recall}

Jin-Hyung Cho, Sam D. Rendall and Jesse M. Gray

Learn. Mem. 2017, 24:

Access the most recent version at doi:10.1101/Im.044446.116

Supplemental http://learnmem.cshlp.org/content/suppl/2017/03/16/24.4.169.DC1
Material

References This article cites 70 articles, 13 of which can be accessed free at: http://learnmem.cshlp.org/content/24/4/169.full.html\#ref-list-1

Creative This article is distributed exclusively by Cold Spring Harbor Laboratory Press for the Commons License first 12 months after the full-issue publication date (see http://learnmem.cshlp.org/site/misc/terms.xhtml). After 12 months, it is available under a Creative Commons License (Attribution-NonCommercial 4.0 International), as described at http://creativecommons.org/licenses/by-nc/4.0/.

Email Alerting Receive free email alerts when new articles cite this article - sign up in the box at the Service top right corner of the article or click here. 